\title{
Population Genomics of Marine Zooplankton
}

Chapter 19 in: Population Genomics: Marine Organisms

Editors: Om P. Rajora and Marjorie Oleksiak

Ann Bucklin (Corresponding author)

Department of Marine Sciences, University of Connecticut

1080 Shennecossett Road, Groton, CT 06340 USA

Tel. 860-405-9260; Fax 860-405-9153

Email: ann.bucklin@uconn.edu

Kate DiVito

Dept. of Molecular and Cell Biology, University of Connecticut

354 Mansfield Rd (U-1131), Storrs, CT 06269 USA

Email:kate.divito@uconn.edu

Irina Smolina

Marine Ecology Research Group

Faculty of Biosciences and Aquaculture, Nord University

Universitetsalléen 11, 8026 Bodø, Norway

Email: irina.smolina@nord.no

Marvin Choquet

Marine Ecology Research Group

Faculty of Biosciences and Aquaculture, Nord University

Universitetsalléen 11, 8026 Bodø, Norway

Tel: +47 755177 56; Fax: +47 94890853

Email: marvin.choquet@nord.no

Jennifer M. Questel

Department of Marine Sciences, University of Connecticut

1080 Shennecossett Road, Groton, CT 06340 USA

Tel. 860-405-9255; Fax 860-405-9153

Email: jennifer.questel@uconn.edu

Galice Hoarau

Marine Ecology Research Group

Faculty of Biosciences and Aquaculture, Nord University

Universitetsalléen 11, 8026 Bodø, Norway

Tel: +47 75517497

Email: galice.g.hoarau@nord.no

Rachel J. O’Neill

Center for Genome Innovation and Institute for Systems Genomics

Dept. of Molecular and Cell Biology, University of Connecticut

354 Mansfield Rd (U-1131)

Storrs, CT 06269 USA

Tel: 860-486-6031; Fax: 860-486-1936

Email: rachel.oneill@uconn.edu

Submitted: August 22, 2017 


\section{Population Genomics of Marine Zooplankton}

Chapter 19 in: Population Genomics: Marine Organisms

Editors: Om P. Rajora and Marjorie Oleksiak

\section{Table of Contents}

\subsection{Abstract}

\subsection{Introduction}

19.2.1. Introduction to population genomics

19.2.2. Introduction to marine zooplankton

19.2.2.1. Biodiversity

19.2.2.2. Biogeography

19.2.2.3. Life history

19.2.3. Genomic resources for marine zooplankton

19.2.3.1. Published genomic resources

19.2.3.2. Genome sizes of zooplankton

19.2.3.3. Mitogenomes

19.2.3.4. Transcriptomic resources

\subsection{Applications of population genomics for marine zooplankton}

19.3.1. Population genetic diversity and structure

19.3.2. From population genetics to population genomics

19.3.3. Genomic basis of adaptation

19.3.4. Metagenetics and metabarcoding

19.4. Case studies of marine zooplankton

19.4.1. Calanus finmarchicus (Copepoda)

19.4.2. Centropages typicus (Copepoda)

19.4.3. Tigriopus californicus (Copepoda)

19.4.4. Acartia tonsa (Copepoda)

19.4.5. Euphausia superba (Euphausiacea)

19.4.6. Meganyctiphanes norvegica (Euphausiacea)

19.4.7. Pleurobrachia bachei (Ctenophora)

19.4.8. Spadella cephaloptera (Chaetognatha)

19.4.9. Salpa thompsoni (Tunicata)

\subsection{Present-day challenges and future opportunities}

19.5.1. Additional genomic resources for marine zooplankton species

19.5.2. Sampling zooplankton in the global ocean

19.5.3. Species identification

19.5.4. Sequencing small-size organisms

19.5.5. Genomic basis of adaptation

\subsection{Acknowledgements}

\subsection{Table Legends}

\subsection{Figure Legends}

\subsection{Literature Cited}




\section{Population Genomics of Marine Zooplankton}

Ann Bucklin, Kate DiVito, Irina Smolina, Marvin Choquet, Jennifer M. Questel, Galice Hoarau, and Rachel J. O’Neill

\subsection{Abstract}

The exceptionally large population size and cosmopolitan biogeographic distribution that distinguish many - but not all - marine zooplankton species generate similarly exceptional patterns of population genetic and genomic diversity and structure. The phylogenetic diversity of zooplankton has slowed the application of population genomic approaches, due to lack of genomic resources for closelyrelated species and diversity of genomic architecture, including highly-replicated genomes of many crustaceans. Use of numerous genomic markers, especially single nucleotide polymorphisms (SNPs), is transforming our ability to analyze population genetics and connectivity of marine zooplankton, and providing new understanding and different answers than earlier analyses, which typically used mitochondrial DNA and microsatellite markers. Population genomic approaches have confirmed that, despite high dispersal potential, many zooplankton species exhibit genetic structuring among geographic populations, especially at large ocean-basin scales, and have revealed patterns and pathways of population connectivity that do not always track ocean circulation. Genomic and transcriptomic resources are critically needed to allow further examination of micro-evolution and local adaptation, including identification of genes that show evidence of selection. These new tools will also enable further examination of the significance of small-scale genetic heterogeneity of marine zooplankton, to discriminate genetic “noise” in large and patchy populations from local adaptation to environmental conditions and change.

Keywords: Zooplankton, Population genomics, Transcriptomics, Evolution, Population genetics 


\subsection{Introduction}

\section{II.A. Introduction to population genomics}

Population genomic approaches entail simultaneous sampling of numerous variable loci within a genome and allow inference of locus-specific effects (Baird et al. 2008). These powerful new techniques are transforming our understanding of the population genetics, connectivity, demographic history, and local adaptation of marine organisms (Crawford and Oleksiak 2016; Pogson 2016). Genotyping hundreds to thousands of genetic markers for multiple individuals across populations or species has enabled identification of selectively-neutral markers that can be used for a wide variety of analyses (Luikart et al. 2003; Baird et al. 2008). Discrimination of statistical 'outlier' loci allows examination of the impacts of selection and evidence of local adaptation (Stapley et al. 2010). Whole-genome analysis of non-model organisms has enabled new insights into underlying evolutionary forces. However, significant challenges remain for whole-genome analysis of non-model organisms, thus necessitating and encouraging broad use of approaches that require little or no prior genomic data. These include reduced-representation genomic DNA libraries (Reitzel et al. 2013), genotyping-by-sequencing (Elshire et al. 2011), and exon-capture (Hodges et al. 2007; De Wit et al. 2015; Jones and Good 2016), although the latter requires prior knowledge of gene architecture. In broad view, population genomic approaches have enormous potential to yield significant new understanding of the ecological and evolutionary dynamics of zooplankton and other marine organisms.

\subsubsection{Introduction to marine zooplankton}

19.2.2.1. Biodiversity: The marine zooplankton assemblage includes $~ 6,000$ described species of holoplanktonic metazoan organisms that complete their entire cycle in the water column (Wiebe et al. 2010). The phylogenetic diversity of this assemblage is impressive, with 11 phyla and 27 orders represented (Bucklin et al. 2010b). However, these numbers most likely markedly underestimate the actual biodiversity - perhaps by several orders of magnitude - due to the presence of cryptic variation within geographically widespread species or sibling species swarms, as well as undiscovered species in 
under-sampled or explored habitats (Bucklin et al. 2010a; Beaugrand 2017). Molecular approaches, including DNA barcoding and metabarcoding, are providing important new insights into this 'hidden diversity’ of marine zooplankton (Lindeque et al. 2013; Bucklin et al. 2016).

19.2.2.2. Biogeography: Global patterns of zooplankton biogeographic distributions have been well-characterized for the epipelagic $(0-200 \mathrm{~m})$ zone (Longhurst 2007). The many classical studies form a basis for ongoing examination of climate-driven range changes and regime shifts (deYoung et al. 2008). In contrast, the deep ocean, including the mesopelagic (200 - 1,000 m) and bathypelagic $(1,000-4,000$ m), remains under-sampled and poorly-known (but see Wiebe et al. 2010; Laakmann et al. 2012). Many species exhibit cosmopolitan distributions, with ranges spanning multiple ocean basins and broad latitudinal ranges (Peijnenburg and Goetze 2013). However, there are many exceptions to this oversimplified description, likely resulting from specific habitat requirements, restricted gene flow, or relict populations (Chust et al. 2016). Further complicating analysis of species distributional patterns are rather characteristic high ratios of local-to-global species diversity; a net sample from oceanic waters may contain hundreds of species of copepods or $\sim 10 \%$ of the global total (Kuriyama and Nishida 2006).

19.2.2.3. Life history: Many zooplankton species have life histories entailing multiple stages with different micro-habitat preferences and requirements. Some exhibit alternation of sexual and asexual generations. Most are relatively short-lived organisms, with generation spans from several months to a couple of years. As a group, marine zooplankton are useful indicators of impacts of environmental variability or climate change, since they are rapid-responders in terms of species distribution and abundance. The exceptional diversity of marine zooplankton - in terms of phylogenetic biodiversity, pelagic biogeography, and life history variation - provided a unique opportunity to examine ecological and evolutionary genomic responses. This review will summarize new knowledge resulting from population genomic examination of the genetic diversity and structure, phylogeography and connectivity, demographic history, and local adaptation of marine metazoan holozooplankton. 


\subsubsection{Genomic resources for marine zooplankton}

19.2.3.1. Published genomic resources: It can be argued that there are no universally-accepted model species among the marine zooplankton; in many cases, there are no closely-related model organisms to which extrapolations or comparisons can be made (Ellegren 2014). However, the number of marine zooplankton species targeted for genome-scale studies is growing, including species ranging phylogenetically from the Cnidaria to the Urochordata and including ecologically-important or keystone species for some pelagic ecosystems, such as the Southern Ocean salp, Salpa thompsoni (Jue et al. 2016) (Table 1).

For the most part, marine zooplankton species targeted for reference sequencing and assembly have been identified by their impact to ongoing comparative genomic studies or as part of larger genome consortia. An example of this latter group is the genome sequence for the copepod Eurytemora affinis, a species targeted for sequencing as part of the i5K Pilot Project aimed at sequencing 28 arthropod genomes (i5K Consortium 2013; Eyun et al. 2017). Currently, assembled genomes are available for species representing only a snapshot of some of the major lineages of eukaryotes and a small sampling of the species diversity of the pelagic realm (Table 1). A significant factor in the identification of a target species for a genome assembly effort is the estimated genome size. Notably, all the reference genomes available are from organisms whose genome size estimates are significantly smaller than 1GB, presumably since the depth of coverage required is low enough to represent a feasible investment of resources in terms of fiscal and computational effort. While reference quality assemblies are ideal (e.g., Oikopleura dioica, Denoeud et al. 2010), lower coverage assemblies can still provide a high enough N50value (i.e., the weighted median statistic such that $50 \%$ of the entire assembly is contained in contigs or scaffolds equal to or larger than this value) to afford extensive gene predictions (e.g., Jue et al. 2016).

Recently, mining genome databases such as NCBI and the SRA (Short Read Archive) for partial genome sequences has afforded broader comparisons among species lacking a fully assembled genome.

For example, a newly derived reference for the common estuarine copepod E. affinis was compared to Population Genomics of Marine Zooplankton - Bucklin et al. - August 22, 2017 
short read genomic sequence data from two other copepods, the freshwater cyclopoid copepod, Mesocyclops edax (SRX246444 and SRX246445; Sun et al. 2014) and the North Atlantic copepod, Calanus finmarchicus) (SRX456026; Smolina et al. 2014), revealing species-specific adaptations of the chemosensory related gene families to environments (Eyun et al. 2017).

19.2.3.2. Genome size in the zooplankton: The average estimated genome sizes (haploid nuclear DNA contents) of holoplankton species are in general far above 1 GB (Fig. 1) and varies more than 900fold, from 0.07 GB in Oikopleura dioica (Appendicularia) to 63.2 GB in Ampelisca macrocephala (Amphipoda). Variation of genome sizes in marine zooplankton is especially large within the Copepoda with > 370-fold variation among species (Leinaas et al. 2016; Madoui et al. 2017) followed by Ostracoda and Malacostraca with around 80-fold and 70-fold variation of genome size among species, respectively (Gregory 2017; Jeffery et al. 2017). To date, genome size has been investigated for 115 species of zooplankton, with poor representation of important phyla, including Chaetognatha, Cnidaria, Ctenophora, Mollusca and Chordata.

Several trends or patterns are emerging from genomic analyses of crustaceans, although only a few species have been studied to date. First, a positive relationship between genome size (C-value) and body size has been observed in copepods (McLaren et al. 1988; Wyngaard and Rasch 2000), amphipods (Hessen and Persson 2009), and ostracods (Jeffery et al. 2017). However, there is considerable variability in genome size both among species of similar body size (Gregory et al. 2000; Leinaas et al. 2016) and within species due to environmental conditions (McLaren et al. 1988; Escribano et al. 1992; Leinaas et al. 2016). Second, genome size has been associated with specific habitats and environmental conditions. Marine crustaceans are likely to have larger genomes than freshwater and terrestrial ones (Jeffery 2015; Alfsnes et al. 2017); within the marine realm, polar species tend to have larger genomes compared to temperate species (Hessen and Persson 2009; Jeffery 2015; Leinaas et al. 2016). Jeffery (Jeffery 2015) hypothesizes that such large genomes may result from the expansion of transposable elements and other repetitive elements, due to relaxed selection for rapid development or reduced constraints on body size in Population Genomics of Marine Zooplankton - Bucklin et al. - August 22, 2017 
predictable and stable marine polar environments, compared to more fluctuating environments.

Causes and mechanisms of genome size variability and particularly expansion of genome sizes are still not known. Among eukaryotes, genome size is positively correlated with gene number, average intron size, and number of introns per genome (Elliott and Gregory 2015). The main drivers of genome size expansion are suggested to be whole-genome duplication (polyploidization) or partial duplication events and proliferation of noncoding elements (Dufresne and Jeffery 2011).

Information on genome size, genome sequence, and karyotype is sparse in marine zooplankton, limiting our understanding of genome evolution. Nevertheless, evidence from insects and crustaceans suggest that accumulation of transposable and repetitive elements may be the primary contributor to their large genome sizes (Alfsnes et al. 2017), while polyploidization is probably not the most common driver of genome evolution in zooplankton (Gregory and Hebert 1999). For example, species of the copepod genera Calanus and Pseudocalanus exhibit quantum shifts in genome size (C-values) within each genus, but share similar chromosome complements (McLaren et al. 1989).

Partial duplication or amplification of genomic regions may be common in large genomes of zooplankton, particularly for ribosomal rDNA and protein-coding genes. Among eukaryotes, rDNA copy number correlates positively with genome size (Prokopowich et al. 2003). For species of Calanus, 18S rDNA gene copy number has been found to approximately double between C. finmarchicus (15,300 copies; 2C = 12.95 pg) and $C$. glacialis (33,500 copies; 2C = 24.20 pg; Wyngaard et al. 1995). Transcriptomic analysis has indicated the presence of multi-copy gene families originating from multiple duplications of an ancestral gene in copepods (Lenz et al. 2014; Yang et al. 2014), euphausiids (Toullec et al. 2013; Sales et al. 2017), and pteropods (Maas et al. 2015; Thabet et al. 2017).

19.2.3.3. Mitochondrial genomes: Fragments of mitochondrial DNA were among the first molecular tools used to tackle questions related to zooplankton species identification, phylogenetics, phylogeography, and population genetics. For example the cytochrome oxidase sub-unit I is preferentially used as a barcode for metazoan (Schindel and Miller 2005), and has been used frequently 
for marine zooplankton (Bucklin et al. 2007, 2010a, 2011; Blanco-Bercial et al. 2014).

Recent technological advances are allowing routine sequencing of whole mitochondrial genomes (mitogenomes), with marked increase in the power of phylogenetic and phylogeographic analyses compared to use of short mtDNA sequences. Applications such as shotgun sequencing on genomic DNA using high throughput sequencing technologies afford opportunities to capture other genomes that may be resident within a sample, such as mitochondrial DNA. Given the smaller target genome size (12-20KB), mitogenomes are easier to subsample from larger datasets or to assemble using a PCR-build approach (Maricic et al. 2010; Hahn et al. 2013; Kollias et al. 2015).

Mitogenomics is a promising field of research that will contribute new insights into the phylogenetic history and evolution of planktonic species. For example, sequencing the mitogenome of the chaetognath, Spadella cephaloptera, allowed resolution of the phylogenetic position of the chaetognaths within Protostome lineages (Papillon et al. 2004). Only a few mitogenomes have been published thus far - especially when the species diversity of zooplankton is considered - and within those, unexpected features appear to be more common than previously thought. Mitogenomes are publicly available for a number of ecologically-important species representing diverse phylogenetic lineages of marine zooplankton (Table 2), and additional complete mitochondrial assemblies may be found within incompletely-explored genomic data. Nonetheless, the sequencing and assembly of complete mitogenomes of marine zooplankton species has progressed at a much slower pace than other for vertebrate groups (Genome 10K Community of Scientists 2009; GIGA Community of Scientists 2014).

In animals, the mitogenome is relatively well conserved, with 36 or 37 genes, including two for rRNAs, 22 for tRNAs and 12 or 13 for protein-coding genes. The mitogenomes available for marine zooplankton species indicate a general trend of high intra- and interspecific variability. Rearrangement of gene order is exceptionally common and has been documented in amphipods (Ki et al. 2010) and ctenophores (Kohn et al. 2012), with some of the genes relocated to the nuclear genome (Pett et al. 2011). Copepods also show marked variability among congeneric species and among genera (Fig. 2; Jung et al. 
2006; Minxiao et al. 2011). The most exceptional cases of mitochondrial variability documented to date are in the chaetognaths, Spadella cephaloptera and Sagitta elegans, for which natural populations exhibit unprecedented levels of intra-specific divergence (Marlétaz et al. 2017).

The variability observed in the mitogenomes of different species/lineages is also apparent in the genes content and size of these mitogenome (Table 2). The smallest mitogenome reported is the ctenophore, Mnemiopsis leidyi, with only $10 \mathrm{~kb}$, which is missing 25 genes (Pett et al. 2011). Within the chaetognaths, mitogenomes are also very reduced compared to other metazoans, missing several common genes (Helfenbein et al. 2004; Papillon et al. 2004). On the other hand, the longest mitogenomes documented belong to the Copepods, up to $20 \mathrm{~kb}$ (Minxiao et al. 2011). Several mitogenomes were found to contain multiple copies of some sequences (Ogoh and Ohmiya 2004; Burton et al. 2007), or short tandem repeats, similar to microsatellites (Shen et al. 2011).

19.2.3.4. Transcriptomic resources: For some species, especially those with large, duplicated and/or evolutionarily-divergent genomes, analysis of transcriptomes has proven more feasible, accurate and cost-effective (De Wit et al. 2016). Transcriptomic data have the further advantage of allowing identification and annotation of target genes used in the examination of genomic micro-evolution and local adaptation (Havird and Santos 2016). Transcriptomic data, including partial reference transcriptomes are available for a number of marine zooplankton species (Table 3).

\subsection{Applications of population genomics for marine zooplankton}

\subsubsection{Population genetic diversity and structure}

Although many zooplankton species exhibit broad geographic distributions and appear to have high dispersal potential, both biological and physical environmental processes may limit gene flow. Previous studies have revealed significant genetic differentiation of geographic populations of marine organisms over a range of spatial scales (Hellberg 2009; Weersing and Toonen 2009). Two general principles may be gleaned from many studies of zooplankton population genetics: first, zooplankton are quite variable in many different molecular characters; second, this variability is resolved into genetically- 
divergent, geographically-distinct populations for only some species and at some temporal and spatial scales (Peijnenburg and Goetze 2013).

Ocean processes that are thought to be significant for population genetic structuring of zooplankton are currents, persistent eddies, ocean gyres and other physical ocean structures at the mesoscale (10s to $100 \mathrm{~s} \mathrm{~km}$ ) to large scale (100s to $1000 \mathrm{~s} \mathrm{~km})$. The physical structure of the ocean can alter the timing of reproduction and mortality events, providing biological barriers to gene flow. Geological features - continents, islands and other landforms, continental shelves, seamounts, and ocean ridges - may form natural barriers to dispersal. In contrast, cosmopolitan species, which range from $40^{\circ} \mathrm{N}$ to $40^{\circ} \mathrm{S}$ and are found in every ocean basin, may have few barriers to dispersal throughout their range. These species may exhibit large-scale spatial population genetic structure due to isolation by distance (i.e., reproductive isolation resulting when the geographic range of the species far exceeds the dispersal potential of an individual).

The temporal stability of population genetic diversity and structure is an important consideration and useful metric. Since zooplankton are subject to transport in ocean currents, temporal stability of population genetic characters may indicate retention of local populations or local recruitment. An unfortunate aspect of many studies of zooplankton populations is the collection of samples from different regions during different years, thus confounding spatial and temporal variation. In relatively few studies, spatial and temporal contributions to population genetic structure have been analyzed separately using appropriately-collected samples (Goetze et al. 2015; Iacchei et al. 2017).

Patterns of genetic diversity and structure have been examined over a wide range of spatial scales for species representing many lineages of the zooplankton assemblage. Some species have been shown to be panmictic, such as Pelagia noctiluca (Stopar et al. 2010) and Euphausia superba (Deagle et al. 2015). Many species exhibit geographic variation reflecting geographic barriers and/or circulation patterns: e.g., Tigriopus californicus (Renaut and Dion-Côté 2016), Eukrohnia hamata (Kulagin et al. 2014), and Caecosagitta macrocephala (Miyamoto et al. 2010), to name a few. A number of species show largePopulation Genomics of Marine Zooplankton - Bucklin et al. - August 22, 2017 
scale patterns of genetic diversity associated with latitudinal gradients (e.g., Francisco et al. 2014) and among ocean basins, including Eukrohnia hamata (Miyamoto et al. 2012), Pleuromama abdominalis (Hirai and Tsuda 2015), and Oithona similis (Cornils et al. 2017).

The occurrence and significance of small-scale genetic patchiness in marine zooplankton populations remain a subject of study and disagreement. Such variability has been considered to reflect the genetic "noise” of large and under-sampled populations of copepods (e.g., Goetze et al. 2015). Smallscale heterogeneity was considered to reflect advective transport from diverse recruitment sources in the Antarctic krill, Euphausia superba (Batta-Lona et al. 2011).

Due to nearly-universal application in population genetic studies, hierarchical analysis of variance using Wright’s F-statistics related measures (Excoffier et al. 1992) provides useful benchmarks for comparisons among species, regions, and environments. However, F-statistics have assumptions that are surely not met for zooplankton (Hellberg 2009), including genetic equilibrium conditions, symmetrical migration, and stable populations. The usefulness of F-statistics is further limited by the very large population sizes of many zooplankton, which result in relatively larger confidence intervals for very small F values (Waples 1998), and thus a lack of statistical significance for high gene flow species (see Waples et al. 2008). At least partly for this reason, population genetic studies of marine species have also employed various measures of oceanographic distance (Hansen and Hemmer-Hansen 2007; McGovern et al. 2010; Alberto et al. 2011; Schunter et al. 2011) and approaches such as seascape genetics (Galindo et al. 2010).

Until recently, population genetic studies have most frequently been conducted with markers representing a very small fraction of the genome, such as individual mitochondrial or nuclear genes and microsatellites (see reviews by Avise 2009; Hellberg 2009; Peijnenburg and Goetze 2013). Rates of divergence and amounts of variation differ among these markers, but many studies have documented significant genetic differentiation of zooplankton populations at large, ocean basin scales using mitochondrial DNA (e.g., Goetze 2005; Goetze and Ohman 2010; Miyamoto et al. 2010; Blanco-Bercial Population Genomics of Marine Zooplankton - Bucklin et al. - August 22, 2017 
et al. 2011a; Miller et al. 2012; Norton and Goetze 2013; Dawson et al. 2015) and microsatellite markers (Bolte et al. 2013; Andrews et al. 2014). A number of studies have used mitochondrial DNA markers to resolve population structure of zooplankton populations associated with physical barriers to gene flow, including ocean circulation, for copepods (Aarbakke et al. 2011; Blanco-Bercial et al. 2011b, 2014) and euphausiids (Bucklin et al. 1997; Zane et al. 1998, 2000; Zane and Patarnello 2000; Papetti et al. 2005; Patarnello et al. 2010).

Both mitochondrial and microsatellite markers continue to be widely used for population genetic analysis of zooplankton, allowing useful comparisons among diverse species and ocean environments. Studies using single markers have limitations, not least that results may differ among studies using different markers (Avise et al. 2016). In addition to their limited analytical power, studies using multiple markers can yield discordant conclusions. In particular, the haploid nature and uniparental inheritance of mitochondrial markers, and consequent smaller effective population size, may generate differences from results using nuclear markers (Toews and Brelsford 2012).

Population genomic approaches can also be used for phylogeographic analysis (i.e., the description of the geographical distributions of the genetic lineages within a population or species; Avise 2009; Avise et al. 2016). Such analysis allows for the characterization of dispersal and quantitative estimation of the rate and direction of exchange among populations. Recent reviews of larval dispersal and population connectivity (Cowen and Sponaugle 2009) and gene flow (Hellberg 2009) in the ocean have provided comprehensive assessment and analyses for marine organisms. Quantitative estimates of population persistence and directional (asymmetric) migration can also entail approaches that are less sensitive to lack of population stability and non-equilibrium conditions, typical of marine organisms (Knowles 2009). Analysis of patterns and pathways of gene flow has revealed that patterns of population connectivity of marine organisms do not always mimic major ocean currents (Kool et al. 2013; Riginos et al. 2016), even for zooplankton (Blanco-Bercial and Bucklin 2016; Questel et al. 2016).

Phylogeographic analysis can also provide a window into the evolutionary history of a population 
or species. Results can be interpreted to estimate and understand the age of the lineage in terms of time to coalescence (i.e., the common ancestral gene from which all current copies of the gene are descended), as well as imprints of demographic history on populations and species (Knowles 2009). Among marine zooplankton, mitochondrial markers have been used most regularly to infer demographic history (e.g., Peijnenburg et al. 2005; Aarbakke et al. 2014; Cornils et al. 2017), including marine invasions (Cristescu 2015; Lee 2016; Sherman et al. 2016), population expansions and contractions (Edmands 2001), geographic isolation giving rise to speciation events (Lee 2000; Peijnenburg et al. 2004; Miyamoto et al. 2010), and divergence of genetic lineages following major global climate events (Papadopoulos et al. 2005; Blanco-Bercial et al. 2011b; Milligan et al. 2011).

\subsubsection{From population genetics to population genomics}

Recent advances in High-Throughput Sequencing (HTS) have created exceptional new opportunities for analysis of population genetic diversity and structure of natural populations. Tens of thousands of genomic Single Nucleotide Polymorphisms (SNPs) can be detected and screened for use as genetic makers of population genetic diversity and structure (Helyar et al. 2011; Reitzel et al. 2013). Such population genomic approaches are being widely used among marine organisms (Bierne et al. 2016), including fishes (Hemmer-Hansen et al. 2014). In addition, HTS is yielding both deep coverage and nucleotide-level resolution in simultaneous or multiplexed analysis of numerous genes (e.g., Bybee et al. 2011). Such population genomic approaches are yielding a new view of population structure and connectivity of marine species, based on statistical discrimination of neutral, selected, and hitchhiker loci (Gagnaire and Gaggiotti 2016).

Over the last three decades, genetic research has showed continuous development and a high turnover of molecular markers, from partial DNA sequencing, restriction fragment length polymorphism (RFLP), random amplified polymorphism detection (RAPD) and amplified fragment length polymorphism (AFLP) to microsatellites, insertion-deletion polymorphism (InDel), and single nucleotide polymorphism (SNP; Schlötterer et al. 2014). Historically, development of markers was difficult and 
expensive for non-model organisms. However, the advent of HTS has revolutionized this by allowing the genome-wide markers in any organism and for low cost (Ekblom and Galindo 2011). Although simultaneous discovery and genotyping of genome-wide variation has become feasible for tens of individuals with small genome sizes $(<1 \mathrm{~GB})$, the individual sequencing of hundreds of individuals with large genomes remains prohibitively expensive (Narum et al. 2013). In addition, sequencing of the complete genome for all individuals is often unnecessary and inflates the bioinformatics demands (Narum et al. 2013). Therefore, for many studies including population genomics, it is more efficient to sequence a limited number of targeted loci, thus increasing their coverage and chance to detect true polymorphism (Ekblom and Galindo 2011).

A revolutionizing solution to address this situation was the development of genotyping-bysequencing (GBS) approaches that allow sequencing with high throughput technology of a targeted fraction of the genome via various reduced-representation protocols (see review by Crawford and Oleksiak 2016). These approaches result in discovery and simultaneous genotyping of thousands of SNPs even in species with large genomes and little or no previous genomic information. GBS relies on various reduced-representation protocols to target a genome fraction, but four protocols are currently the most popular: RNA-seq, Ampli-seq, Cap-seq (i.e., capture enrichment), and RAD-seq (Davey and Blaxter 2010; Reitzel et al. 2013). Published reduced representation genomic resources are currently available for several species of marine zooplankton, such as the copepods, Tigriopus californicus (Foley et al. 2011), Calanus finmarchicus (Smolina 2015), and Centropages typicus (Blanco-Bercial and Bucklin 2016); and the euphausiid, Euphausia superba (Deagle et al. 2015). The number of studies using reduced representation for population genomics in marine zooplankton may be expected to expand in the near future.

The power of genomic SNPs for resolution of regional- to large-scale population structure of zooplankton has been demonstrated for several key species (see Case Studies, below). A large-scale population genetic analysis using genomic SNPs demonstrated that RAD-seq methods performed poorly Population Genomics of Marine Zooplankton - Bucklin et al. - August 22, 2017 
in the copepod, Calanus finmarchicus, which has a large and complex genome (Smolina 2015). Subsequent studies of this species using targeted resequencing (e.g., Cap-seq) showed promise for accurate SNP identification and detection of genetic structuring for this species (Choquet et al., unpubl. data). Similarly, a study of the copepod, Centropages typicus, by Blanco-Bercial and Bucklin (2016) using 1,000s of genomic SNPs obtained by RAD-seq revealed evidence of population structure, in contrast to an earlier study based on mitochondrial gene sequences (Castellani et al. 2012).

Genomic SNPs that show evidence of selection can provide markers of micro-evolution and local adaptation, including identification of the key genes involved in these phenomena. The use of many thousands of genomic markers will also enable further examination of the significance of small-scale genetic heterogeneity of marine zooplankton, including distinguishing genetic "noise” in large and patchy populations from local adaptation to environmental conditions. Large-scale SNP genotyping studies remain very scarce in zooplankton species, but as more studies based on these approaches are published, it will be important to resolve differing conclusions based on the various technical approaches and genetic markers employed.

\subsubsection{Genomic basis of adaptation}

Population genomic approaches have provided powerful new tools for detection of impacts of selection and evidence of local adaptation (Stapley et al. 2010). Patterns of variation of genomic markers can be statistically evaluated for non-neutrality and correlation with population dynamic, environmental, and evolutionary conditions and drivers (Gagnaire et al. 2015). Non-neutral markers showing evidence of selection can be used to reveal adaptation of populations to local conditions across a species range (Whitehead 2012), although other evolutionary drivers, including introgression and hitchhiking, can also cause such departures from neutrality for genomic traits (Bierne et al. 2013). Nielsen et al. (2009) concluded that few published studies have convincingly documented that non-neutral traits reflect local adaptation, citing reviews by Hedrick (2006) and Levasseur et al. (2007). Recent advances in statistical analysis of genomic markers are enabling more sensitive and accurate detection of local adaptations 
(Gayral et al. 2013; Savolainen et al. 2013; De Wit et al. 2015), although these are much more powerful for species with well-characterized genomes, which allows exome capture and sequencing (Jones and Good 2016).

Patterns of differential gene expression can also provide useful insights into local adaptive responses of marine organisms to environmental conditions. There are a number of such studies of marine zooplankton, including target-gene and whole-transcriptome analyses of differential gene expression patterns associated with stress responses and environmental variability (Lauritano et al. 2012; Schoville et al. 2012; De Pittà et al. 2013; Smolina et al. 2015, 2016; Roncalli et al. 2016; Batta-Lona et al. 2017). The genetic and genomic bases of such gene expression differences have received considerable attention (see review by Romero et al. 2014).

\subsubsection{Metagenetics and metabarcoding}

The exceptional challenge of species identification in zooplankton assemblages, resulting from both phylogenetic diversity and sibling species swarms, has encouraged the development of genetic approaches for both stand-alone and integrative use with morphological taxonomic methods (Bucklin et al. 2016). Metagenetic and metabarcoding approaches analyze DNA recovered from environmental samples and can reflect the biodiversity of entire pelagic communities (de Vargas et al. 2015), with the advantage of detecting 'hidden diversity' of marine zooplankton (Lindeque et al. 2013). These studies use 'universal' PCR primers to amplify one or more gene regions for high throughput sequencing yielding tens of millions of sequences, which are subsequently resolved into operational taxonomic units (OTUs) that can either be matched to reference databases for identification of taxa or used for various statistical measures of biodiversity (Leray and Knowlton 2016). Metabarcoding studies of marine zooplankton have ranged from analysis of the global ocean (Bik et al. 2012; de Vargas et al. 2015) to studies focused on particular habitats and ecosystems, such as estuaries (Abad et al. 2016), the Red Sea (Pearman and Irigoien 2015), among others. Challenges remain for quantitative analysis of taxa using metabarcoding, although recent studies have shown some correlation between OTU frequency and taxon biomass (Hirai 
et al. 2015; Sun et al. 2015).

The continuing development of sequencing technologies may soon allow a full metagenomics approach, where DNA extracted from environmental samples is sequenced and whole genomes are reconstructed from the data. These data will be invaluable resources for diverse population genomic approaches, including analysis of population genetic diversity and structure, detection of loci under selection, and genomic bases of adaptations of zooplankton species to environmental variation. Currently, both technical and bioinformatics challenges limit use of metagenomics to species with small genomes, such as the copepod, Oithona nana (Madoui et al. 2017).

\subsection{Case studies of marine zooplankton}

Population genomic approaches, entailing simultaneous sampling of numerous variable loci within a genome and the inference of locus-specific effects (Black et al. 2001; Luikart et al. 2003), are only very recently being used for analysis of marine zooplankton. Comparison between results from population genetic studies using single-markers (usually mitochondrial or microsatellite DNA) and HTS genomic markers are particularly useful to evaluate the power and precision of population genomic approaches for analysis of genetic structure, connectivity, demographic history, and local adaptation.

Several of the marine zooplankton species analyzed using population genomic approaches belong to the crustacean Subclass Copepoda, which comprises more species than any other zooplankton group, including many that are ecologically important, numerically predominant, and geographically widespread. Genomic analysis of copepods has been a focus of research, although progress has been hampered by the exceptionally large genome sizes of many species (Bron et al. 2011; Wyngaard et al. 2011; Jeffrey 2015).

19.4.1. Calanus finmarchicus (Copepoda): The planktonic copepod Calanus finmarchicus (Fig.

3) is thought to be the most abundant metazoan in the ocean; the species is ubiquitous in coastal and open ocean cold-temperate regions of the North Atlantic Ocean (Planque et al. 1997); within this area, the species may contribute $>70 \%$ of total copepod biomass (Head et al. 2003) and occupies a pivotal position in ocean food webs (Falk-Petersen et al. 2007). Population genetic studies using mitochondrial DNA 
(e.g., Bucklin et al. 1996) and microsatellites (Provan et al. 2009) have shown high levels of gene flow and little or no significant population genetic structure at any spatial scale. Studies using SNPs in targeted gene regions suggested genetic differentiation among samples from different water masses and ocean basins (Bucklin and Kaartvedt 2000; Unal and Bucklin 2010 Fig. 4). Population genomic analyses of C. finmarchicus have been impeded by the large size of its genome (C-value $=6.48 \mathrm{pg}$; McLaren et al. 1988), typical of crustaceans. Smolina (2015) used a genotyping-by-sequencing approach (ddRADseq; Peterson et al. 2012) to characterize genomic SNPs in pooled samples of $C$. finmarchicus collected across the North Atlantic Ocean. Significant population differentiation was observed among locations, although the allelic nature of the SNP variants in the pooled samples could not be confirmed due to the highlyreplicated genome (Smolina 2015). An ongoing study by this group is analyzing genomic SNPs in targeted gene regions to allow confirmation of allelic variation despite genome size (Choquet et al. 2017a). A partial reference transcriptome for the species (Lenz et al. 2014) is allowing evaluation of evidence of local adaptation based on transcriptomic and target gene analysis (e.g., Roncalli et al. 2016).

19.4.2. Centropages typicus (Copepoda): Blanco-Bercial and Bucklin (2016) used genomic SNPs detected by 2b-RADseq analysis (Wang et al. 2012) to examine population genetic structure of the copepod Centropages typicus (Fig. 5) in the North Atlantic Ocean. Thousands of genomic SNP markers were identified; loci showing evidence of positive selection were removed from analysis (Foll and Gaggiotti 2008). Statistical analysis of molecular variance (Excoffier and Lischer 2010) revealed significant differences between continental shelf populations of the NE and NW Atlantic populations, in contrast with an earlier study by Castellani et al. (2012), which showed no structuring using a mitochondrial COI gene region, but some differentiation of NE and NW Atlantic populations based on a nuclear rRNA internal transcribed spacer (ITS) region. Genotyping-by-sequencing (RADtag sequences) of C. typicus yielded 675 loci used by Blanco-Bercial and Bucklin (2016) to test hypotheses of dispersal and directional migration (Beerli 2012). Among five different gene flow models (Fig. 6), the full migration model showed the highest support. These results demonstrate the power of population genomic Population Genomics of Marine Zooplankton - Bucklin et al. - August 22, 2017 
approaches to resolve patterns and pathways of dispersal of a high gene flow species in a dynamic and complex current system. Such analyses can also be used to examine the genomic basis of observed local adaptation of this species to environmental variability among regions or along a latitudinal gradient (Carlotti et al. 2007).

19.4.3. Tigriopus californicus (Copepoda): The tidepool copepod, Tigriopus californicus, shows exceptional levels of small-scale population genetic heterogeneity associated with the habitat structure of the rocky shoreline, based on studies using mitochondrial markers (Rawson et al. 2000; Burton et al. 2007). The species may be considered to be a model species for studies of evolutionary divergence and local adaptation (Raisuddin et al. 2007). The rapid rate of evolutionary divergence of mitochondrial genes is thought to contribute to the potential for local adaptation, but may also cause low hybrid fitness by disrupting gene complexes (Burton et al. 2013). The mitochondrial genome has been sequenced (Barreto et al. 2011; Pereira et al. 2016). A genomic SNP linkage map (Foley et al. 2011) and a partial draft genome (https://i5k.nal.usda.gov/Tigriopus_californicus) serve as useful resources for characterizing population genetic diversity and structure. More recently, the capacity of this species to adapt to local condition and stressors has been explored using population genomic and transcriptomic approaches (Lima and Willett 2017; Pereira et al. 2017).

19.4.4. Acartia tonsa (Copepoda): The rapid cladogenesis - and perhaps cryptic speciation - of the estuarine copepod, Acartia tonsa, has been extensively studied along the Atlantic coastline of the USA using mtDNA marker genes (Caudill and Bucklin 2004; Chen and Hare 2008, 2011). The species has been intensively studied in laboratory culture, partly as food for aquacultured fish (Jepsen et al. 2017) and partly as a model organism for studies of the genetic basis of local adaptation and micro-evolution (Drillet et al. 2008). Responses to environmental stressors have been examined using genomic and transcriptomic approaches (Nilsson et al. 2014; Petkeviciute et al. 2015; Rahlff et al. 2017).

19.4.5. Euphausia superba (Euphausiacea): The Antarctic krill, Euphausia superba (Fig. 7), is a keystone species of the Southern Ocean pelagic ecosystem, whose high abundance, markedly patchy Population Genomics of Marine Zooplankton - Bucklin et al. - August 22, 2017 
distribution, and swarming behavior have long been a subject of research (Siegel and Watkins 2016). The population genetic consequences of this exceptional life history have been studied over many decades using varied markers, including allozymes, mitochondrial DNA, and microsatellites. Many studies have revealed similar patterns of genetic diversity, whereby variation within locations far outweighs that between locations, with consistent evidence of lack of large-scale population differentiation (see review by Jarman and Deagle 2016). Two studies using mitochondrial markers found evidence of significant small-scale patchiness: Batta-Lona et al. (2011) hypothesized that genetic differences among samples resulted from advective transport from distinct recruitment centers in the Western Antarctic Peninsula region. Zane et al. (1998) found genetic differentiation between samples collected in the Weddell Sea and South Georgia. Although the statistical significance of these findings has been questioned (see Bortolotto et al. 2011), small-scale patchiness - or genetic “noise” - may be a consequence of the life history of this unique species and/or evidence of local adaptation. Evidence of micro-evolution and local adaptation by Antarctic krill has been shown in genetic and functional analysis of target genes, including thioredoxin (Li et al. 2017), clock genes (Jones and Good 2016), heat shock proteins (Papot et al. 2016), and opsins (Biscontin et al. 2016), among others. Population genomic analysis of Antarctic krill was introduced by Deagle et al. (2015), who examined circum-Antarctic genetic diversity and structure using both RADseq and mitochondrial (ND1 and COI) markers. The large and highly-replicated genome of E. superba (47.7 GB, Jeffery 2012) prevented discrimination of allelic variation versus that between copies at separate loci (see above), which was addressed by analysis of sequence counts at variable nucleotide sites, rather than the derived genotypes. This study confirmed earlier findings of the large-scale panmixia of Antarctic krill populations (Deagle et al. 2015).

\subsubsection{Meganyctiphanes norvegica (Euphausiacea): The northern krill Meganyctiphanes}

norvegica (Fig. 8) is abundant throughout the North Atlantic and western Mediterranean Sea. The species exhibits clear genetic differentiation among geographic populations based on various mtDNA markers (see review by Patarnello et al. 2010). Consistent evidence of local adaptation of the species, including 
enzyme activities (Saborowski and Buchholz 2002), is now being analyzed using differential gene expression made possible by a reference transcriptome (Maas and Blanco-Bercial 2016).

\subsubsection{Pleurobrachia bachei (Ctenophora): A draft genome of the ctenophore Pleurobrachia} bachei (Fig. 9) revealed the possible preservation of 'ancient molecular toolkits' (Moroz et al. 2014), which are lost in other lineages. The exceptional nature of the genomic architecture of this species can provide new understanding of the genomic basis of their evolutionary success and potential for adaptation. Integrative and comparative analysis of genomic and transcriptomic data of this and another ctenophore species Mnemiopsis leidyi demonstrated the phylogenetic position of the phylum as the first metazoan lineage (Ryan et al. 2013; Moroz et al. 2014).

19.4.8. Spadella cephaloptera (Chaetognatha): Arrow worms are predatory zooplankton that occupy key positions in pelagic food webs. The phylum comprises many species with cosmopolitan-butdisjunct biogeographical distributions, which has allowed interesting comparisons among species. Population genetic diversity and structure of several chaetognath species have been explored using both mtDNA and microsatellites (Peijnenburg et al. 2004, 2006; Faure and Casanova 2006; Miyamoto et al. 2010; Kulagin et al. 2014). Large-scale studies have also allowed examination of the demographic histories of the species (Peijnenburg et al. 2005). Analysis of the mitochondrial genome of Spadella cephaloptera (Fig. 10) yielded evidence of exceptional intraspecific variation (Marlétaz et al. 2017), and resolved the phylogenetic position of the Chaetognatha within Protostome lineages (Papillon et al. 2004). 19.4.9. Salpa thompsoni (Tunicata, Thaliacea): The Southern Ocean salp Salpa thompsoni (Fig. 11 ) is a pivotal species in the pelagic ecosystem of Antarctic regions, including the Western Antarctic Peninsula, one of the fastest warming regions of the world oceans. A reference transcriptome for $S$. thompsoni is available, although only $18 \%$ of the 216,931 sequences were associated with predicted, hypothetical, or known proteins (Batta-Lona et al. 2017). Another recent study (Jue et al. 2016) produced a preliminary reference genome for the species, identified more than $50 \%$ of sequences, and generated both SNP variant and INDEL predictions as a resource for future phylogenetic and population studies. 
The genome of this species shows evidence of a rapid evolutionary rate - consistent with other Urochordata (Denoeud et al. 2010; Tsagkogeorga et al. 2012). An initial survey of small RNAs revealed the presence of known, conserved miRNAs, novel miRNA genes, and unique piRNA for various developmental stages (Jue et al. 2016), suggesting possible genomic bases of the successful adaptation of the species to the changing climate of the Southern Ocean.

\subsection{Present-day challenges and future opportunities}

\subsubsection{Additional genomic resources for marine zooplankton species}

Pelagic zones represent one of the largest (by volume) habitats on Earth, with highly diverse and ecologically important assemblages of zooplankton, which can serve as early warning indicators of climate change. Genomic resources are needed to facilitate both intra- and interspecies comparative studies of genetic diversity and structure, phylogeography, demographic history, and adaptive evolution. Importantly, marine zooplankton provide a diverse and useful assemblage to move forward novel studies of the genomic basis of adaptation and evolutionary divergence. Yet the exceptional phylogenetic diversity of marine zooplankton exacerbates the challenges of ensuring that reference genomes are available for abundant and ecologically-important species or their close relatives.

Whole-genome sequencing initiatives should cover a wide range of genome sizes to uncover trends in genome evolution and new elements of genome organization. For instance, sequencing of the salp genome revealed novel miRNA genes and unique piRNAs (Jue et al. 2016), while the genome of Pacific sea gooseberry, Pleurobrachia bachei, is apparently lacking the canonical miRNA machinery and HOX genes (Moroz et al. 2014).

Stimulating discoveries are anticipated from sequencing the exceptionally large genomes of many crustaceans, including euphausiids, copepods, and amphipods, which may reveal novel regulation of

repetitive elements, functional divergence of gene duplication and concomitant novel functions of various gene copies, and correlation between genome size and DNA methylation levels in metazoans (e.g., Lechner et al. 2013). From a practical perspective, even low-coverage genomes will increase the Population Genomics of Marine Zooplankton - Bucklin et al. - August 22, 2017 
robustness of population genomic approaches by facilitating a diverse range of methods, including insilico digestion of genome sequences for RAD-seq techniques, higher mapping rates for DNA and RNAderived sequences, and the development of baits for sequence capture experiments.

Despite their ecological importance in pelagic food webs and their phylogenetic diversity, marine zooplankton have been - and continue to be - largely ignored in the prioritization of species for genomic and transcriptomic analysis. For example, a list of top priority species for reference genome determination from Voolstra et al. (2017) includes only one marine zooplankton species, the mid-water shrimp, Acanthephyra purpurea.

\subsubsection{Sampling zooplankton in the global ocean}

Sampling zooplankton accurately and effectively is a challenge due both to the nature of the pelagic habitat and the frequently immense population sizes of the organisms compared to sampling capacity. It is essential to keep in mind that planktonic organisms most usually occur in patchy distributions, and that some of them are able to avoid the sampling equipment. The origin of these planktonic assemblages or patches has been discussed over many years (e.g., Levin and Segel 1976) and some experimental studies have shown species-specific patterns (Omori and Hamner 1982). Avoidance behaviors also vary among species, and a number of studies have shown that net size and design can markedly impact avoidance and improve the accuracy of sampling of dense and diverse assemblages (Wiebe 1968; Skjoldal et al. 2013; Wiebe et al. 2013). Novel instrumentation designs are now allowing pairing of net sampling with optical and acoustical technologies to allow adaptive sampling of target species of particular interest and importance.

\subsubsection{Species identification}

Accurate and precise identification of species is critical for any study, yet for most zooplankton groups this goal is challenging - at best. Morphological identification has been shown to be unreliable for numerous species, including sibling species of the copepods Pseudocalanus (Bailey et al. 2015) and Calanus (Choquet et al. 2017b). Both transcriptomic and genomic resources are invaluable in allowing 
the design of rapid and inexpensive protocols for accurate discrimination and identification of sibling and cryptic species of marine zooplankton (e.g., Smolina et al. 2015).

\subsubsection{Genomic analysis of small-sized organisms}

Zooplankton species are often very small and thus the yield of DNA extractions is limited. This is not an issue for current HTS methods, which usually require a very small amount of DNA (10s ng). The ongoing development of new sequencing platforms and technologies will likely allow longer sequencing reads and thus better genome and transcriptome assemblies. There is a continuing need to ensure that even the tiniest organisms will be amenable to any new developments in sequencing technologies and instrumentation.

\subsubsection{Genomic basis of adaptation}

Marine environments are experiencing rapid changes in critically-important processes and parameters, including temperature, light penetration, nutrient availability and ocean acidification, among many others. The resultant changes in species physiological condition, ecological functioning, and biogeographical distribution and abundance will inexorably alter pelagic ecosystems in trajectories that are difficult to predict. How species may acclimate and/or adapt to environmental change, and how their interactions within the pelagic food web may be altered, can be examined at many levels. A powerful and important approach lies in examining the underlying genomic mechanisms that facilitate successful adaptation to changing environmental conditions. Although any given species may be uniquely impacted by the physical and biological parameters accompanying shifts in global climate profiles, processes involved in responses to climate change at the molecular level may share common features across species, such as the evolution of gene networks associated with environmental stress responses. Genomic resources are proving instrumental in garnering new insights into organism - environment interactions, including responses to environmental variability associated with climate change. However, we still lack a fundamental understanding of genomic features that afford plasticity and facilitate adaptive responses. These challenges can only be met with comprehensive genomic and transcriptomic resources that will 
afford comparative analysis to investigate the mechanisms underlying the responses of marine zooplankton to the changing environmental conditions throughout the global ocean.

\subsection{Acknowledgements}

This overview results from collaborative efforts with many colleagues and collaborators. We acknowledge and appreciate the contributions of Leocadio Blanco-Bercial (Bermuda Institute of Ocean

Sciences), Peter H. Wiebe (Woods Hole Oceanographic Institution, USA), Paola Batta-Lona (CICESE, Mexico), and Nathaniel K. Jue (California State University, USA). Photographic images of living zooplankton species were provided by: L.P. Madin (Woods Hole Oceanographic Institution), J.R. Runge (University of Maine, USA), Slotwinski (University of Tasmania), Uwe Kils (Rutgers University, USA), Dave Wrobel (http://jellieszone.com/), and Peter Parks (Image Quest 3-D). Support was provided by the US National Science Foundation to AB and RJO (PLR-1044982) and to RJO (MCB-1613856); support to IS and MC was provided by Nord University (Norway). This review is dedicated to David A. Egloff, whose teaching at Oberlin College (Oberlin, Ohio) inspired - and defined the life trajectory - of so many students, including the lead author (AB). 


\subsection{Table Legends and Tables}

Table 1. Holozooplankton species for which genome assemblies and accompanying statistics are publicly available (as of June 2017). Estimated genome sizes are based on assembly statistics unless otherwise noted.

\begin{tabular}{|c|c|c|c|c|c|c|c|c|c|}
\hline & \multicolumn{3}{|l|}{ Tunicates } & \multicolumn{2}{|l|}{ Ctenophores } & \multicolumn{4}{|l|}{ Copepods } \\
\hline & $\begin{array}{l}\text { Oikopleura } \\
\text { dioica }\end{array}$ & $\begin{array}{l}\text { Oikopleura } \\
\text { dioica }\end{array}$ & $\begin{array}{l}\text { Salpa } \\
\text { thompsoni }\end{array}$ & $\begin{array}{l}\text { Pleurobrachia } \\
\text { bachei }\end{array}$ & $\begin{array}{l}\text { Mnemiopsis } \\
\text { leidyi }\end{array}$ & $\begin{array}{l}\text { Eurytemora } \\
\text { affinis }\end{array}$ & Oithona nana & $\begin{array}{l}\text { Tigriopus } \\
\text { kingsejongensi }\end{array}$ & $\begin{array}{l}\text { Tigriopus } \\
\text { californicus }\end{array}$ \\
\hline & Main assem & Allelic assem & & & & & & & \\
\hline Assembly Name & ASM20953v1 & ASM20955v1 & $\begin{array}{l}\text { Salp Genome } \\
1.0\end{array}$ & $\begin{array}{l}\text { P.bachei_draft_- } \\
\text { genome_v.1.1 }\end{array}$ & $\begin{array}{l}\text { GCA_0002260 } \\
15.1\end{array}$ & Eaff_1.0 & O. nana v.1.0 & NA & TCALIF_v1.0 \\
\hline Estimated Genome Size (MB) & 68.46 & allelic assembly & $602^{\mathrm{a}}$ & 170 & 150 & $616.14^{\mathrm{b}}$ & 85 & 298 & $245^{\mathrm{d}}$ \\
\hline Assembly Size & $70,471,451$ & $45,141,193$ & $318,747,957$ & $156,121,975$ & $155,865,547$ & $494,890,867$ & $85,010,107$ & $305,712,242$ & $184,634,130$ \\
\hline Predicted protein coding Genes & 18,020 & 18,020 & 13,186 & 19,523 & 16,548 & 29,783 & 15,359 & 12,772 & 14,536 \\
\hline Coverage & $14 \mathrm{X}$ & $N / A^{c}$ & $20 x$ & $200 x$ & $160 x$ & $75 x$ & $N / A^{c}$ & $65 x$ & $N / A^{c}$ \\
\hline Number of scaffolds & 1,260 & 4,196 & 478,281 & 21,979 & 5,100 & 6,899 & 4,626 & 27,823 & 2,365 \\
\hline Length of N50 scaffold (bp) & 395,387 & 21,890 & 934 & 20,628 & 187,314 & 862,645 & 400,614 & 159,218 & 298,012 \\
\hline Number of N50 scaffold (L50) & 35 & 478 & 79,492 & 1,646 & 242 & 163 & 60 & $N / A^{c}$ & 180 \\
\hline Number of contigs & 5,917 & 6,678 & 590,021 & 38,864 & 24,884 & 122,625 & 7,437 & 48,368 & 26,175 \\
\hline Length of N50 contig (bp) & 24,932 & 10,847 & 636 & 6,132 & 11,936 & 5,738 & 38,620 & 17,566 & 14,799 \\
\hline Number of N50 contig & 718 & 985 & 136,534 & 6,078 & 3,653 & 19,338 & 463 & $N / A^{c}$ & 3,352 \\
\hline Length of gaps (bp) & $3,938,358$ & $2,655,217$ & $14,945,692$ & $19,276,734$ & $5,525,119$ & $107,316,113$ & $2,943,785$ & $10,474,460$ & $N / A^{c}$ \\
\hline References & $\begin{array}{l}\text { Denoeud et al. } \\
(2010)\end{array}$ & $\begin{array}{l}\text { Denoeud et al. } \\
\text { (2010) }\end{array}$ & $\begin{array}{l}\text { Jue et al. } \\
\text { (2016) }\end{array}$ & $\begin{array}{l}\text { Moroz et al. } \\
(2014)\end{array}$ & $\begin{array}{l}\text { Ryan et al. } \\
\text { (2013) }\end{array}$ & $\begin{array}{l}\text { Eyun et al. } \\
\text { (2017) }\end{array}$ & $\begin{array}{l}\text { Madoui et al. } \\
\text { (2017) }\end{array}$ & Kang et al. (2017) & $\begin{array}{l}\text { https://i5k.nal.usda. } \\
\text { gov/Tigriopus_califo } \\
\text { rnicus }\end{array}$ \\
\hline \multicolumn{10}{|c|}{ a genome size estimate independent of assembly (Jue et al. 2016) } \\
\hline \multicolumn{10}{|c|}{ b genome size estimate independent of assembly (Rasch et al. 2004) } \\
\hline c not available/not provided & & & & & & & & & \\
\hline d genome size estimate independent of ass & embly (Wyngaard an & Rasch 2000) & & & & & & & \\
\hline
\end{tabular}


Table 2: Mitochondrial genomes available for marine zooplankton species, with corresponding lengths.

\begin{tabular}{|c|c|c|}
\hline Taxon and Species & Citation & Length (bp) \\
\hline \multicolumn{3}{|l|}{ Copepoda } \\
\hline Calanus hyperboreus & Kim et al. (2013) & 17,910 \\
\hline Calanus sinicus & Minxiao et al. (2011) & $>20,460$ \\
\hline Paracyclopina nana & Ki et al. (2009) & 15,981 \\
\hline Tigriopus californicus & Burton et al. (2007) & 14,600 \\
\hline Tigriopus japonicus & Machida et al. (2002) & 14,628 \\
\hline Tigriopus sp. & Jung et al. (2006) & 14,301 \\
\hline \multicolumn{3}{|l|}{ Euphausiacea } \\
\hline Euphausia pacifica & Shen et al. (2011) & 16,898 \\
\hline Euphausia superba & Shen et al. (2010) & $>15,498$ \\
\hline \multicolumn{3}{|l|}{ Ostracoda } \\
\hline Vargula hilgendorfii & Ogoh \& Ohmiya (2004) & 15,923 \\
\hline \multicolumn{3}{|l|}{ Amphipoda } \\
\hline Onisimus nanseni & Ki et al. (2010) & 14,734 \\
\hline \multicolumn{3}{|l|}{ Decapoda } \\
\hline Acetes chinensis & Kim et al. (2012) & 15,740 \\
\hline \multicolumn{3}{|l|}{ Cnidaria } \\
\hline Aurelia aurita & Shao et al. (2006) & 16,937 \\
\hline Cassiopea frondosa & Kayal et al. (2011) & 15,949 \\
\hline Chrysaora quinquecirrha & Hwang et al. (2014) & 16,775 \\
\hline \multicolumn{3}{|l|}{ Ctenophora } \\
\hline Mnemiopsis leidyi & Pett et al. (2011) & 10,000 \\
\hline Pleurobrachia bachei & Kohn et al. (2012) & 11,016 \\
\hline \multicolumn{3}{|l|}{ Chaetognatha } \\
\hline Sagitta decipiens & Miyamoto et al. (2010) & 11,121 \\
\hline Sagitta enflata & Miyamoto et al. (2010) & 12,631 \\
\hline Sagitta ferox & Li et al. (2016) & 12,153 \\
\hline Sagitta nagae & Miyamoto et al. (2010) & 11,459 \\
\hline Paraspadella gotoi & Helfenbein et al. (2004) & 11,423 \\
\hline Pterosagitta draco & Wei et al. (2016) & 10,426 \\
\hline Spadella cephaloptera & Papillon et al. (2004) & 11,905 \\
\hline
\end{tabular}


Table 3. Summary of transcriptomic resources for marine zooplankton species. Transcript and gene numbers are indicated as presented in the original study. Note that different methodologies were employed across these datasets (e.g. Trinity, MIRA_Newbler, Evigene, FPKM filtered, etc) that render cross-comparisons of gene and transcript numbers among species equivocal. 


\begin{tabular}{|c|c|c|c|c|c|c|c|c|c|}
\hline Phylum and Species & BioProject & \begin{tabular}{|l|} 
Contig \\
Total
\end{tabular} & $\begin{array}{l}\text { Contig Max } \\
\text { Length }\end{array}$ & \begin{tabular}{|l|} 
Contigs Total \\
Length
\end{tabular} & \begin{tabular}{|l|}
$\begin{array}{l}\text { Contigs } \\
\text { Annotated }\end{array}$ \\
\end{tabular} & Transcripts & N50 & Genes & Citation \\
\hline \multicolumn{10}{|l|}{ Cnidaria } \\
\hline Alatina alata & PRJNA312373 & 31,737 & 32,591 & $48,508,802$ & No & 31,776 & 2,545 & 20,173 & Ames et al. (2016) \\
\hline Rhopilema esculentum & PRJNA318143 & 148,857 & 30,742 & $121,470,903$ & No & NA & NA & NA & Chongbo and Yunfeng (Dir Sub) \\
\hline Aurelia aurita & PRJNA252562 & 252,170 & 46,960 & $180,188,094$ & No & 24,264 & 1,761 & 10,285 & Brekham et al. (2015) \\
\hline \multicolumn{10}{|l|}{ Ctenophora } \\
\hline Mnemiopsis leidyi & PRJNA344880 & 140,842 & 29,348 & $137,638,938$ & No & NA & NA & NA & Sanchez Alvarado, Gotting and Ross (Dir Sub) \\
\hline \multicolumn{10}{|l|}{ Arthropoda: Copepoda } \\
\hline Acartia fossae & & 100,383 & 8,174 & & No & & 769 & & Eyun et al. (2017) \\
\hline Calanus finmarchicus & PRJNA236983 & 28,954 & 2,945 & $10,223,122$ & No & 251,042 & 354 & 13,057 & Smolina et al. (2014) \\
\hline Calanus finmarchicus & PRJNA236528 & 206,012 & 23,068 & $205,455,659$ & Yes & & 1,418 & & Lenz et al. (2014) \\
\hline Calanus finmarchicus & PRJNA231164 & 241,140 & 25,048 & $160,760,719$ & No & & & & Tarrant et al. (2014) \\
\hline Calanus glacialis & PRJNA237014 & 36,880 & 4,021 & $15,748,490$ & No & 242,602 & 471 & 18,387 & Smolina et al. (2014) \\
\hline Calanus glacialis & PRJNA274584 & 54,344 & 7,507 & $33,214,362$ & No & 16,998 & 620 & 16,998 & Ramos et al. (2015) \\
\hline Calanus sinicus & & 69,751 & & & & 69,751 & 1,127 & 43,417 & Yang et al. (2014) \\
\hline Calanus sinicus & & & 3,923 & & No & 29,458 & 513 & & Eyun et al. (2017) \\
\hline Eucyclops serrulatus & PRJNA231234 & 51,528 & 16,342 & $36,645,141$ & No & & & & Cattonaro (Dir Sub) \\
\hline Eurytemora affinis & PRJNA278152 & 107,445 & 26,685 & $142,143,154$ & No & 29,783 & & & Monroe (Dir Sub) \\
\hline Eurytemora affinis & PRJNA242763 & 138,088 & 23,627 & $143,733,589$ & Yes & & & & Almada and Tarrant (Dir Sub) \\
\hline Eurytemora affinis & & 88,104 & 26,685 & & & & & & Eyun et al. (2017) \\
\hline Paracyclopina nana & PRJNA268783 & 60,687 & 27,858 & $95,849,484$ & Yes & 67,179 & 4,178 & 12,474 & Lee et al. (2015) \\
\hline Pseudocalanus acuspes & PRJNA296544 & 207,302 & 12,713 & $59,236,626$ & Yes & 69,555 & 1,348 & 28,879 & De Wit et al. (2016) \\
\hline Tigriopus kingsejongensis & PRJNA283925 & 38,250 & 7,809 & $36,497,199$ & Yes & & & & Lee (Dir Sub) \\
\hline Tigriopus kingsejongensis & & & 23,942 & $28,850,726$ & & 40,172 & 1,093 & 12,772 & Kang et al. (2017) \\
\hline Tigriopus californicus & PRJNA263967 & 12,067 & 13,452 & $14,966,851$ & No & & & & Barreto et al. (2011) \\
\hline Tigriopus californicus & PRJNA263967 & 12,075 & 13,452 & $14,902,878$ & No & & & & Barreto et al. (2011) \\
\hline Tigriopus californicus & & 106,317 & 27,644 & NA & Yes & 106,317 & 2,837 & 12,573 & Periera et al. (2016) \\
\hline Tigriopus californicus & & 60,840 & 8,614 & & & & 1,510 & & Eyun et al. (2017) \\
\hline Tigriopus japonicus & PRJNA274317 & 54,758 & 23,769 & $82,981,758$ & Yes & & 3,565 & & Kim et al. (2015) \\
\hline \multicolumn{10}{|l|}{ Arthropoda: Euphausiacea } \\
\hline Euphausia superba & & & 11,127 & & Yes & 15,347 & 520 & 7,942 & Meyer et al. (2015) \\
\hline Euphausia superba & & 22,177 & 8,515 & & Yes & & & 5,563 & Clark et al. (2011) \\
\hline Euphausia superba & & 133,962 & & $129,183,922$ & Yes & & 1,294 & 27,928 & Sales et al (2017) \\
\hline Euphasia crystallorophias & & 42,632 & & & & & 8,341 & & Toullec et al. (2013) \\
\hline Meganyctiphanes norvegica & PRJNA324094 & 405,497 & 26,644 & $222,530,071$ & No & NA & NA & NA & Maas and Blanco Bercial (Dir Sub) \\
\hline \multicolumn{10}{|l|}{ Arthropoda: Amphipoda } \\
\hline Talitrus saltator & PRJNA297565 & 156,706 & 22,032 & $151,674,147$ & Yes & & 968 & & O'Grady et al. (2016) \\
\hline \multicolumn{10}{|l|}{ Arthropoda: Mysidacea } \\
\hline Neomysis awatschensis & PRJNA287057 & 22,141 & 10,398 & $14,999,154$ & Yes & 22,141 & 801 & & Kim et al. (2016) \\
\hline \multicolumn{10}{|l|}{ Mollusca: Pteropoda } \\
\hline Clio pyramidata & PRJNA231010 & 45,735 & & & & 45,735 & 852 & 30,800 & Maas et al. (2015) \\
\hline Clione limacina & PRJNA314884 & 477,401 & 30,190 & $258,267,445$ & Yes & 300,994 & 816 & 181,879 & Thabet et al. (2017) \\
\hline Limacina antarctica & PRJNA295792 & 81,226 & 7,935 & 59791880 & No & 402,273 & 500 & 81,229 & Johnson and Hoffman (2016) \\
\hline Limacina helicina & PRJNA386290 & 53,121 & 12,358 & $31,790,000$ & Yes & & 796 & & Koh et al. (2015) \\
\hline \multicolumn{10}{|l|}{ Urochordata: Tunicata } \\
\hline \begin{tabular}{|l|} 
Oikopleura dioica \\
\end{tabular} & PRJNA269316 & 54,949 & 23,096 & $66,526,340$ & No & & & & Wang et al. (2015) \\
\hline Oikopleura dioica & PRJNA269317 & 86,898 & & $70,800,000$ & & 57,962 & 1,806 & 16,423 & Wang et al. (2015) \\
\hline Salpa thompsoni & PRJNA279245 & 217,849 & 30,785 & $151,741,986$ & No & 216,931 & 1,163 & 26,413 & Jue et al. (2016); Batta Lona et al. (2017) \\
\hline
\end{tabular}

Population Genomics of Marine Zooplankton - Bucklin et al. - August 22, 2017 


\subsection{Figure Legends}

Figure 1. Distribution of estimated genome sizes in representative holozooplankton phyla. Black dots indicate sequenced genomes. Genome size estimations are from Gregory (2017), Jeffery et al. (2017), Leinaas et al. (2016), Ryan et al. (2014), Moroz et al. (2014), and Madoui et al. (2017).

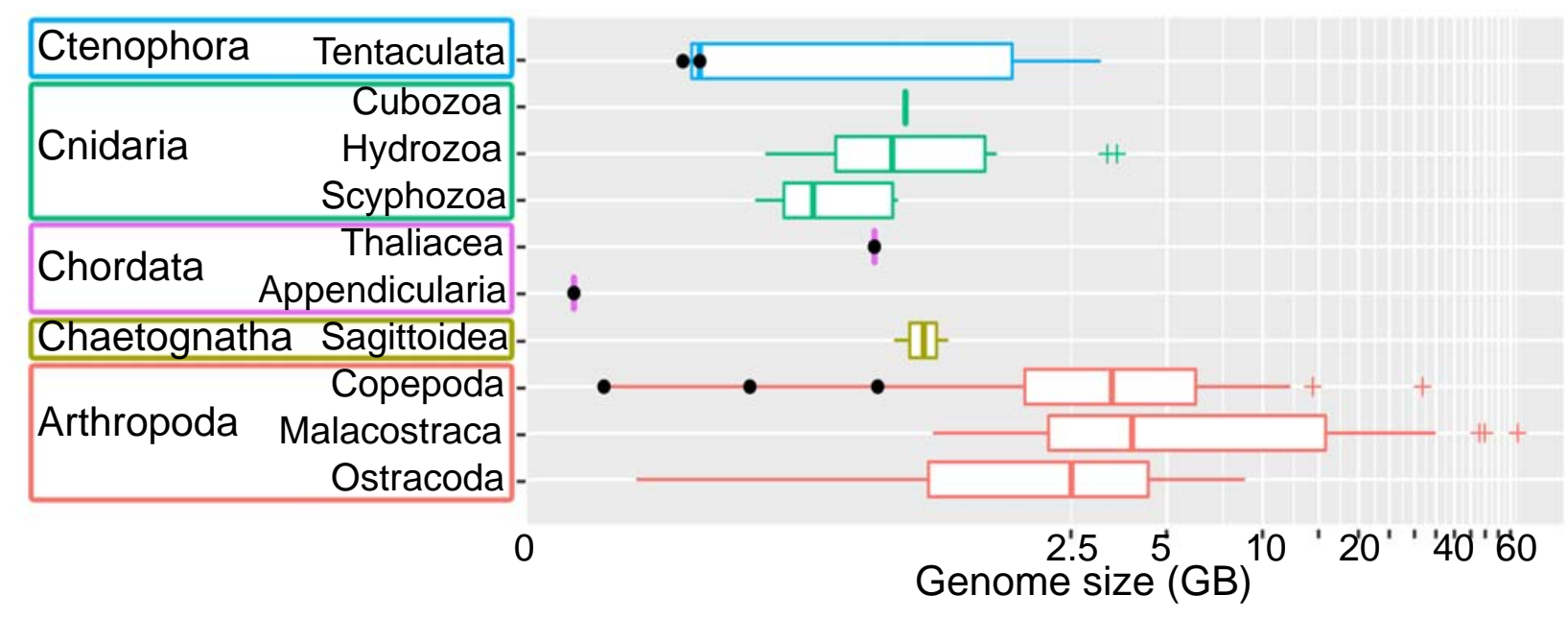


Figure 2: Comparison of the mitochondrial gene order between Calanus sinicus and C. hyperboreus. Only the 13 protein-coding genes are represented. Rectilinear shapes show genes for which the order is conserved between the two species; red lines indicate genes with the same sequence but in reverse order between the species.

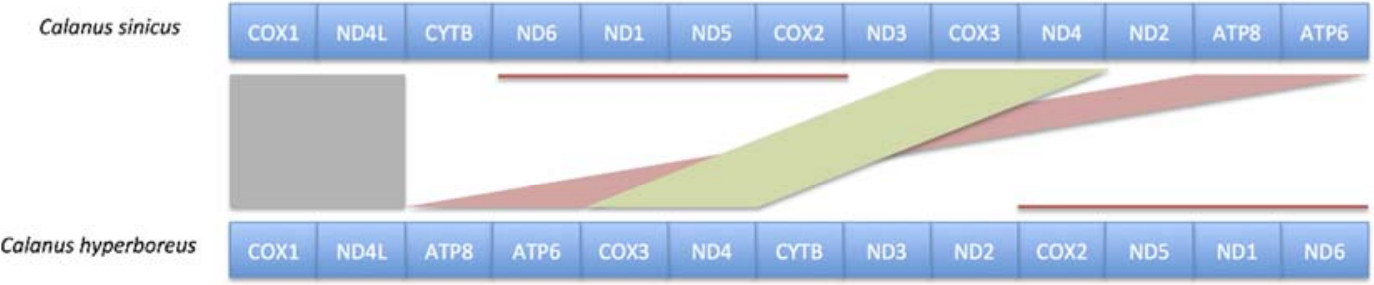


Figure 3. Calanus finmarchicus (Copepod) http://umaine.edu/jrunge/files/2013/12/CV 1 forpublication.jpg (Photo J.R. Runge, University of Maine)

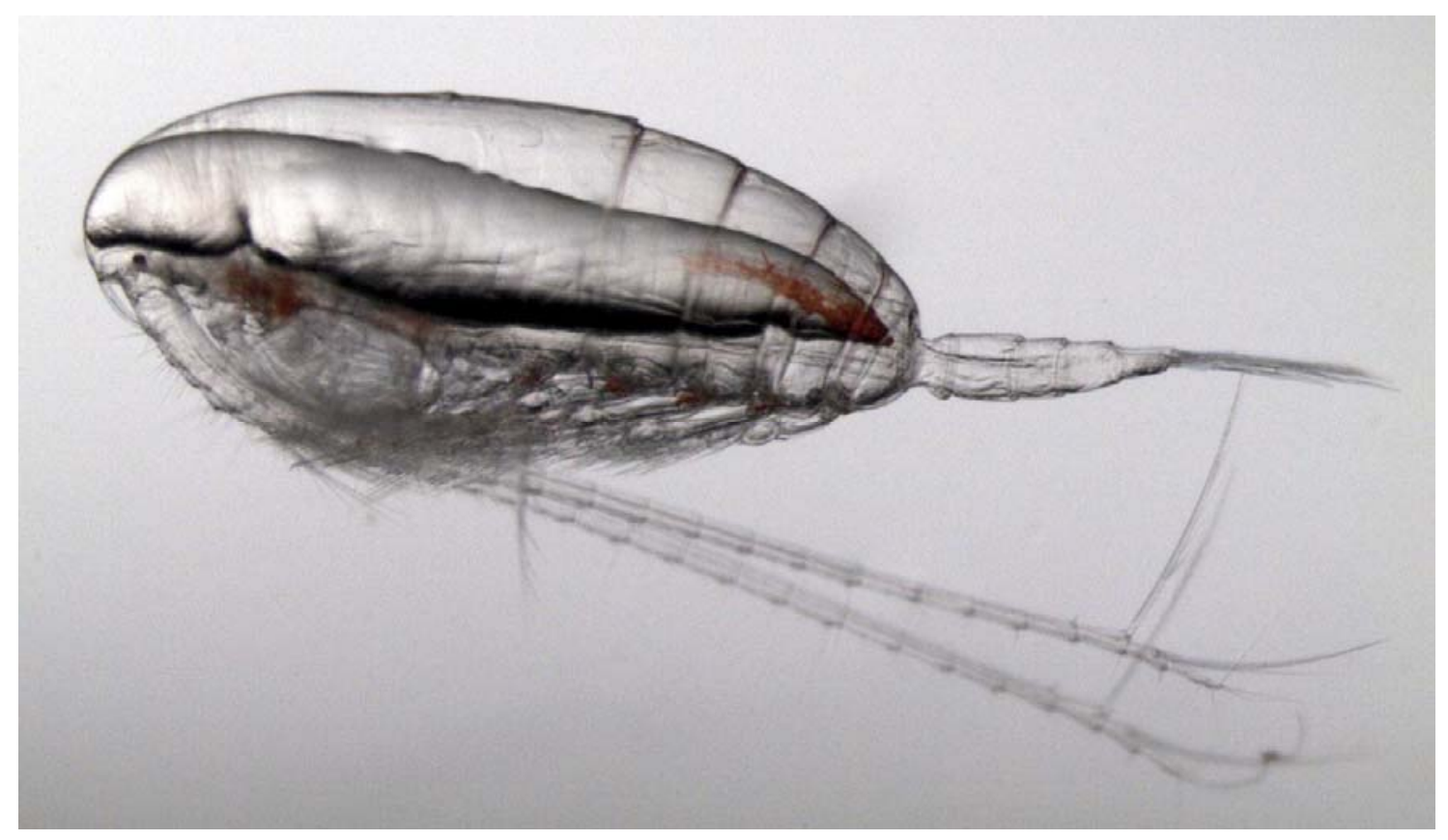


Figure 4. Circulation patterns and bathymetry of the North Atlantic Ocean basin, providing the foundation of the three-gyre hypothesis for basin-scale dispersal of the copepod Calanus finmarchicus. Figure from Wiebe et al. (2009).

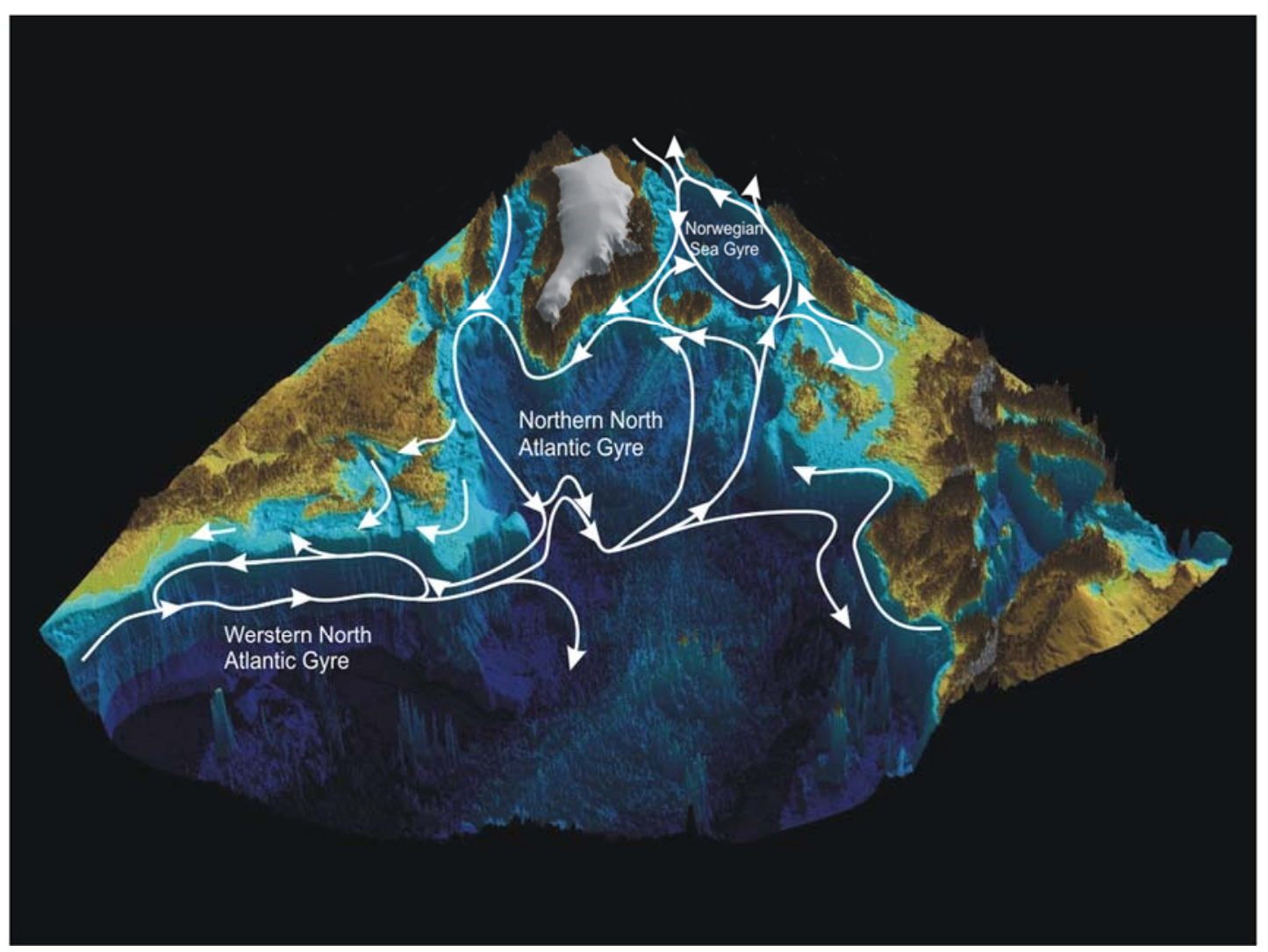


Figure 5. Centropages typicus (Copepod) https://alchetron.com/Centropages-2143715-W (Photo Slotwinski, University of Tasmania)

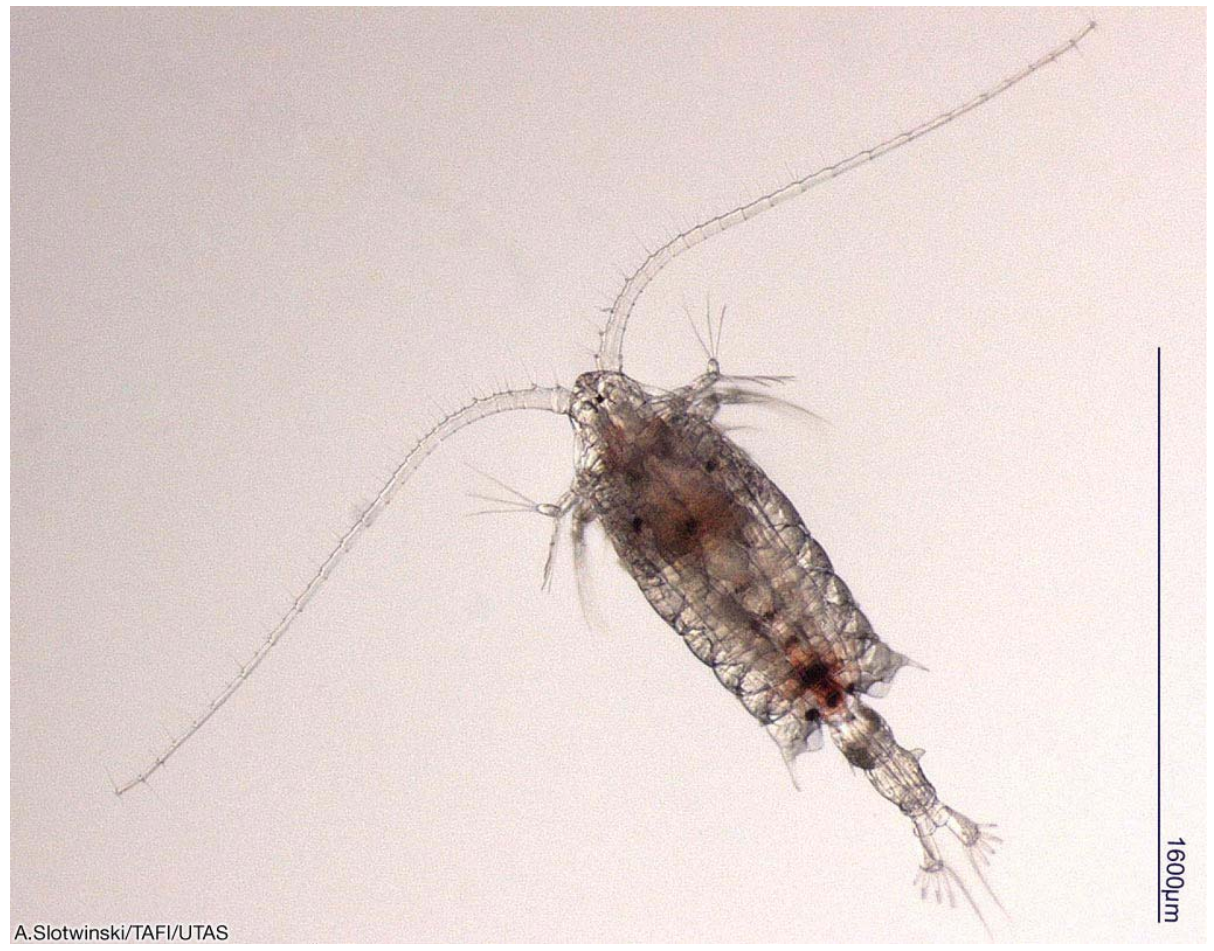


Figure 6. Hypothesized models of gene flow and population connectivity of the copepod Centropages typicus. The full migration model (lower right in diagram) showed the highest likelihood among the considered models based on Bayesian analysis. Figure from Blanco-Bercial and Bucklin (2016).
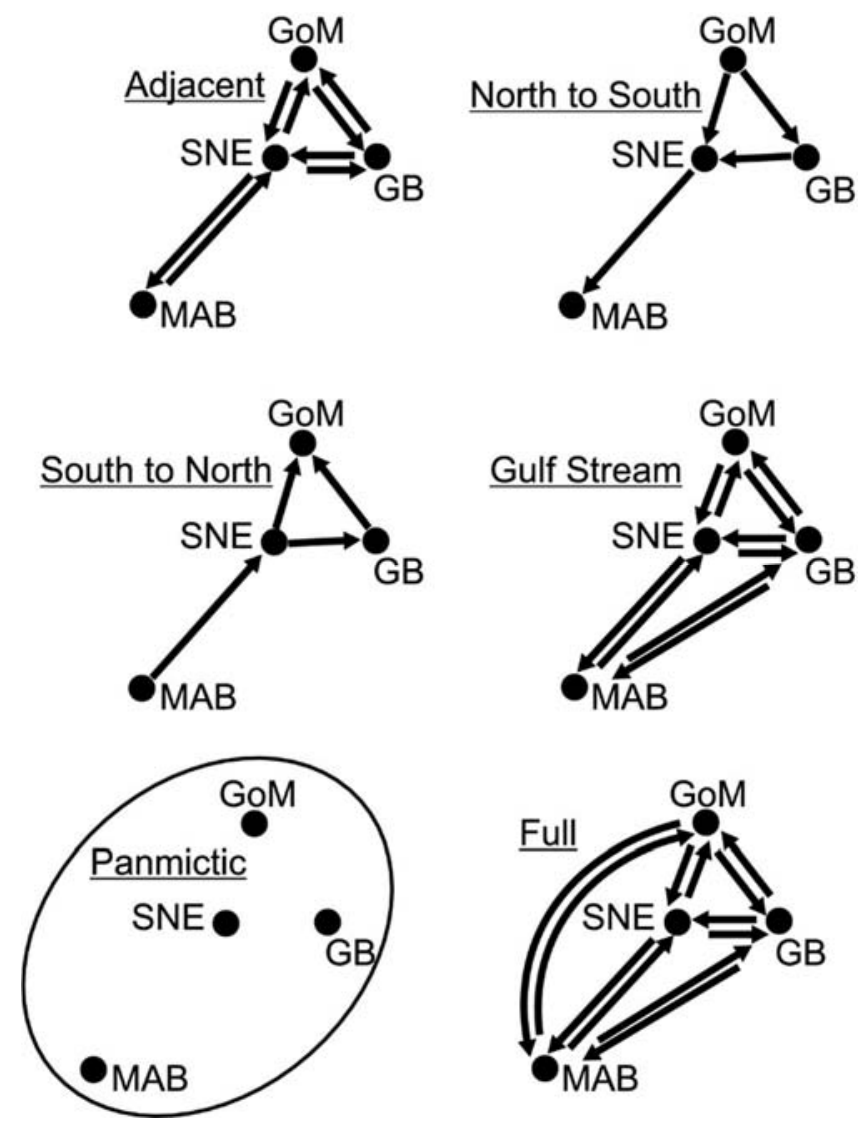
Figure 7. Euphausia superba (Euphausiid) http://www.ecoscope.com/krill/krill4/index.htm (Photo Uwe Kils, Rutgers University, USA)

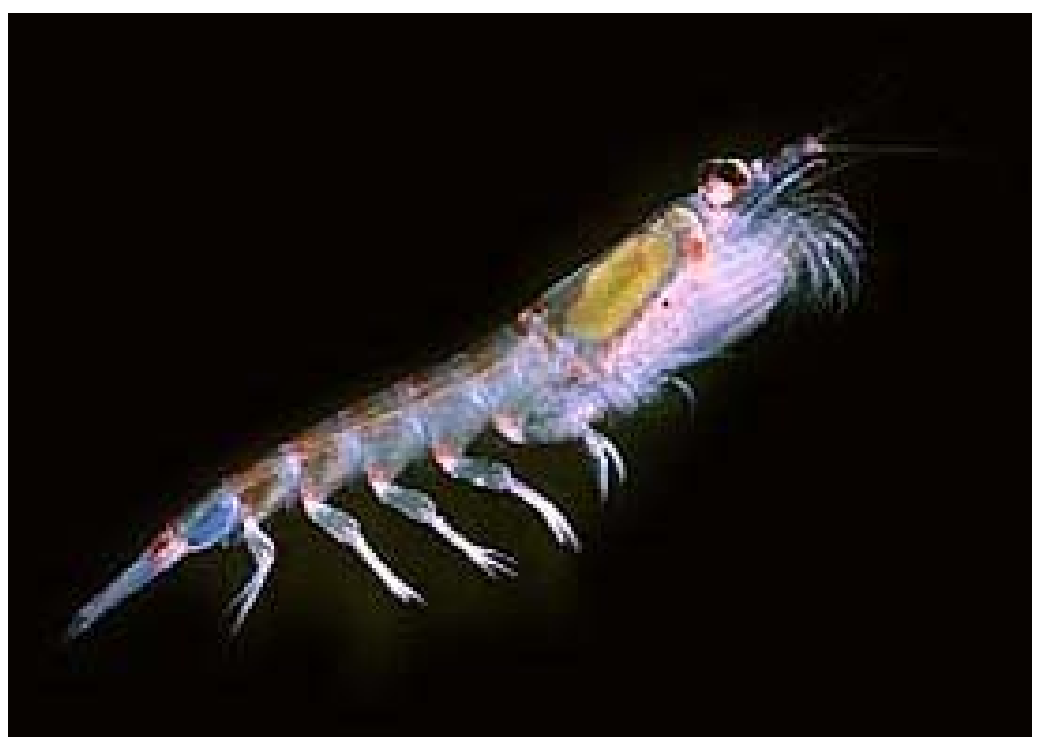


Figure 8. Meganyctiphanes norvegica (Euphausiid)

https://en.wikipedia.org/wiki/Northern krill\#/media/File:Meganyctiphanes norvegica.jpg (Photo Uwe Kils, Rutgers University, USA)

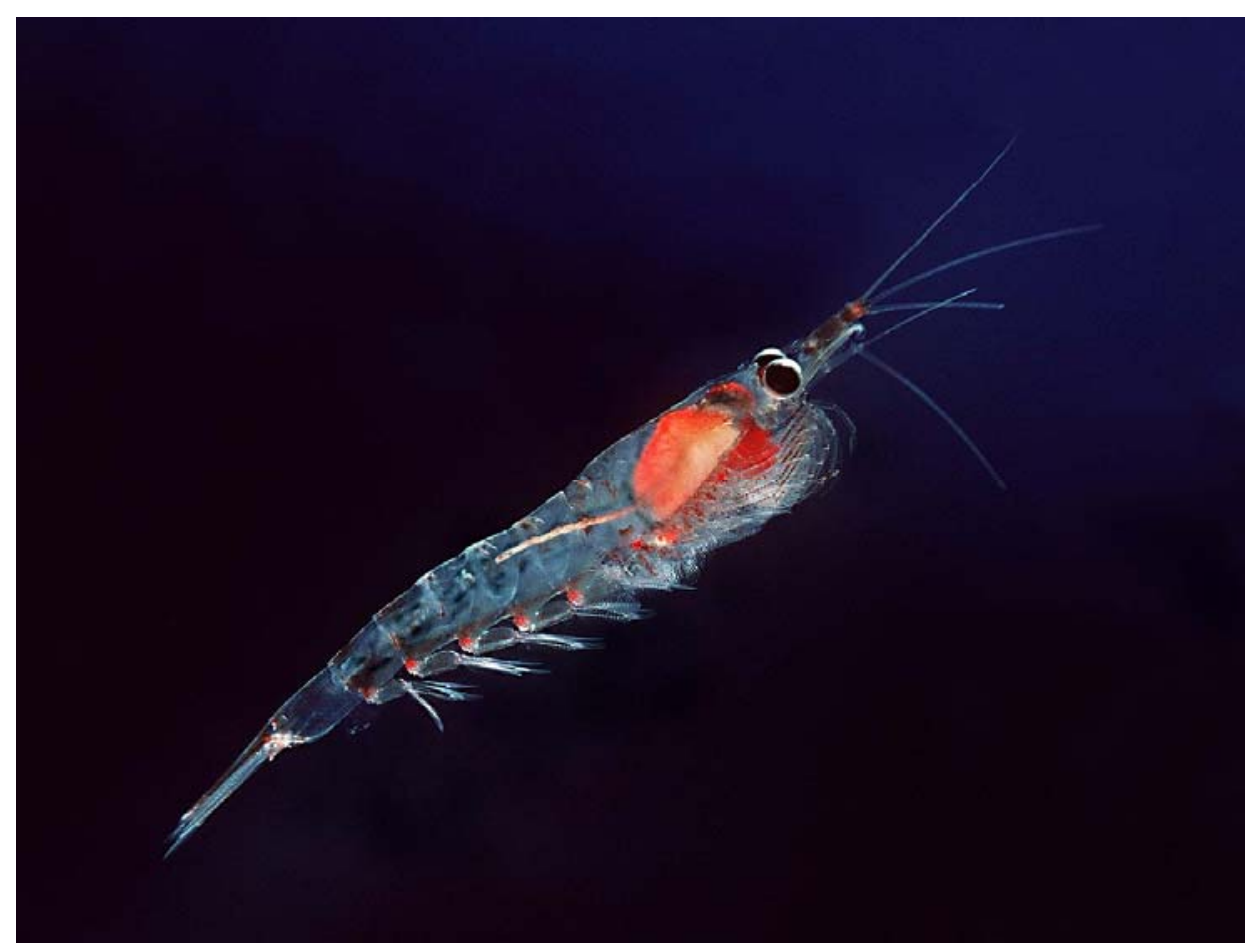


Figure 9. Pleurobrachia bachei (Ctenophora) http://jellieszone.com/ctenophores/pleurobrachia/ (Photo Dave Wrobel)

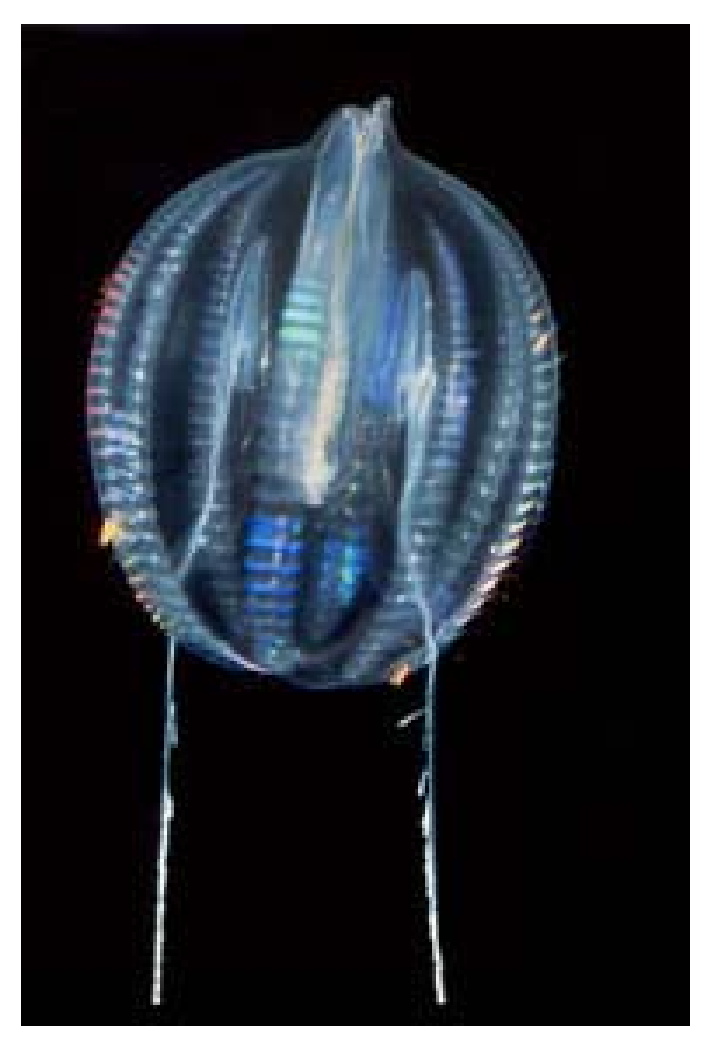


Figure 10. Spadella cephaloptera (Chaetognatha) http://australianmuseum.net.au/image/Arrow-wormChaetognaths (Photo Peter Parks, Image Quest 3-D)

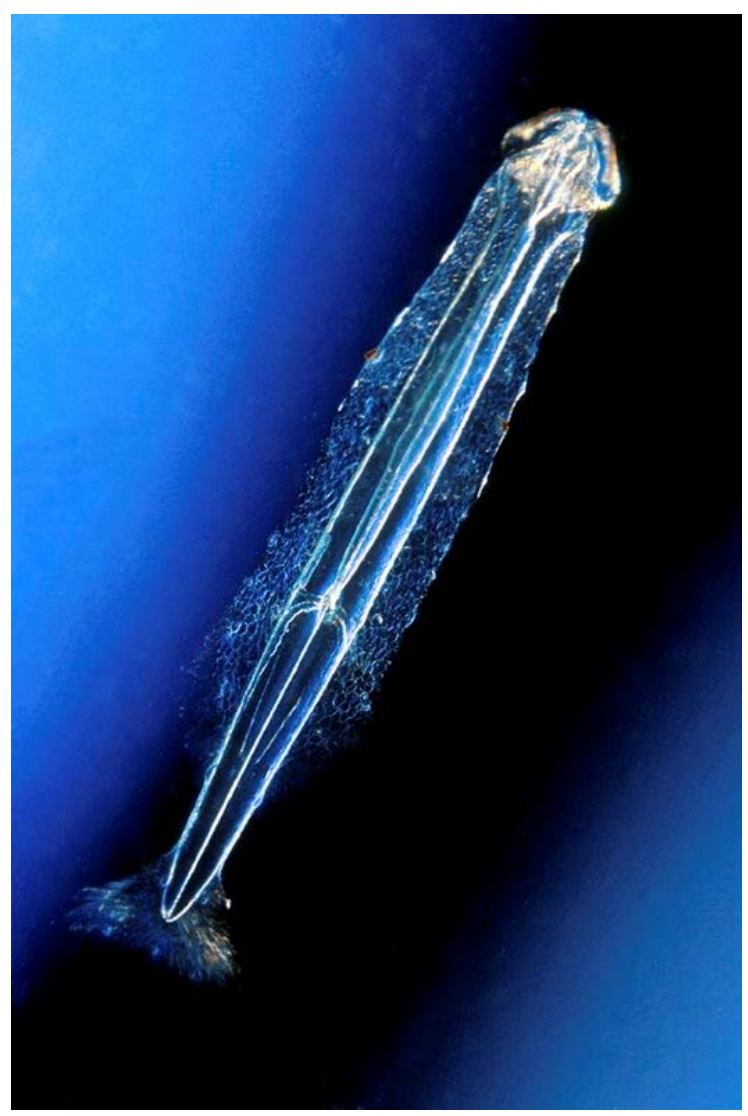


Figure 11. Salpa thompsoni (Tunicata, Thaliacea)

http://www.whoi.edu/cms/images/oceanus/2005/6/v44n1-briefs2-3en 10823.jpg (Photo L.P. Madin, Woods Hole Oceanographic Institution)

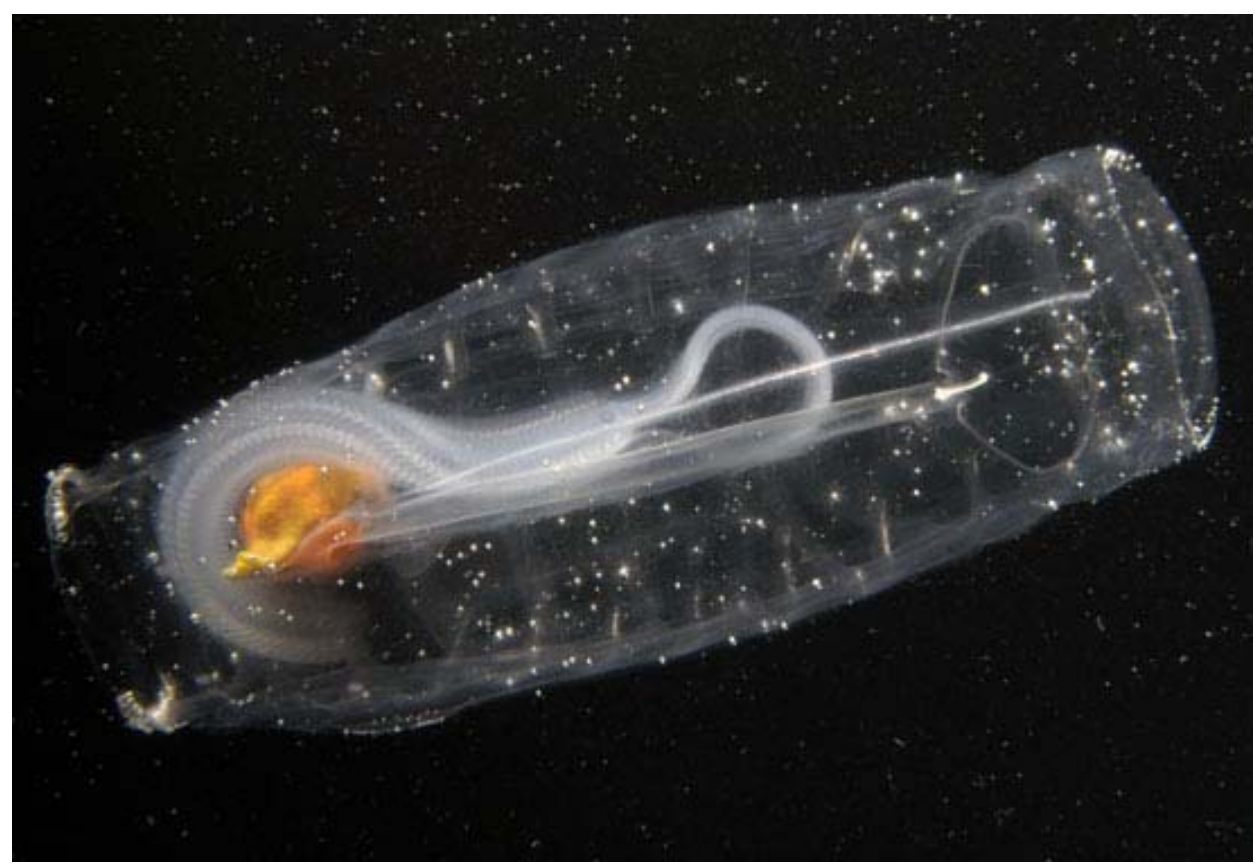




\subsection{Literature Cited}

Aarbakke ONS, Bucklin A, Halsband C, Norrbin F (2011) Discovery of Pseudocalanus moultoni (Frost, 1989) in Northeast Atlantic waters based on mitochondrial COI sequence variation. J Plankton Res 33:1487-1495. doi: 10.1093/plankt/fbr057

Aarbakke ONS, Bucklin A, Halsband C, Norrbin F (2014) Comparative phylogeography and demographic history of five sibling species of Pseudocalanus (Copepoda: Calanoida) in the North Atlantic Ocean. J Exp Mar Bio Ecol 461:479-488. doi: 10.1016/j.jembe.2014.10.006

Abad D, Albaina A, Aguirre M, et al (2016) Is metabarcoding suitable for estuarine plankton monitoring? A comparative study with microscopy. Mar Biol. doi: 10.1007/s00227-016-2920-0

Alberto F, Raimondi PT, Reed DC, et al (2011) Isolation by oceanographic distance explains genetic structure for Macrocystis pyrifera in the Santa Barbara Channel. Mol Ecol 20:2543-2554. doi: 10.1111/j.1365-294X.2011.05117.x

Alfsnes K, Leinaas HP, Hessen DO (2017) Genome size in arthropods; different roles of phylogeny, habitat and life history in insects and crustaceans. Ecol Evol 1-9. doi: 10.1002/ece3.3163

Ames CL, Ryan JF, Bely AE, et al (2016) A new transcriptome and transcriptome profiling of adult and larval tissue in the box jellyfish Alatina alata: an emerging model for studying venom, vision and sex. BMC Genomics 17:650. doi: 10.1186/s12864-016-2944-3

Andrews KR, Norton EL, Fernandez-Silva I, et al (2014) Multilocus evidence for globally distributed cryptic species and distinct populations across ocean gyres in a mesopelagic copepod. Mol Ecol 23:5462-5479. doi: 10.1111/mec.12950

Avise JC (2009) Phylogeography: Retrospect and prospect. J Biogeogr 36:3-15. doi: 10.1111/j.13652699.2008.02032.x

Avise JC, Bowen BW, Ayala FJ (2016) In the light of evolution X: Comparative phylogeography. Proc Natl Acad Sci U S A 113:7957-7961. doi: 10.1073/pnas.1604338113

Bailey J, Rynearson T, Durbin EG (2015) Species composition and abundance of copepods in the 
morphologically cryptic genus Pseudocalanus in the Bering Sea. Deep Sea Res Part II Top Stud Oceanogr in press. doi: 10.1016/j.dsr2.2015.04.017

Baird NA, Etter PD, Atwood TS, et al (2008) Rapid SNP discovery and genetic mapping using sequenced RAD markers. PLoS One 3:1-7. doi: 10.1371/journal.pone.0003376

Barreto FS, Moy GW, Burton RS (2011) Interpopulation patterns of divergence and selection across the transcriptome of the copepod Tigriopus californicus. Mol Ecol 20:560-572. doi: 10.1111/j.1365294X.2010.04963.X

Batta-Lona PG, Bucklin A, Wiebe PH, et al (2011) Population genetic variation of the Southern Ocean krill, Euphausia superba, in the Western Antarctic Peninsula region based on mitochondrial single nucleotide polymorphisms (SNPs). Deep Sea Res Part II Top Stud Oceanogr 58:16521661. doi: 10.1016/j.dsr2.2010.11.017

Batta-Lona PG, Maas AE, O’Neill RJ, et al (2017) Transcriptomic profiles of spring and summer populations of the Southern Ocean salp, Salpa thompsoni, in the Western Antarctic Peninsula region. Polar Biol 40:1261-1276. doi: 10.1007/s00300-016-2051-6

Beaugrand G (2017) Plankton biodiversity and biogeography. In: Castellani C, Edwards M (eds) Marine Plankton: A Practical Guide to Ecology, Methodology, and Taxonomy. Oxford University Press, pp 12-23

Beerli P (2012) Migrate Documentation version 3.2.1. Florida State University, Tallahasee. Florida

Bierne N, Bonhomme F, Arnaud-Haond AS (2016) Dedicated population genomics for the silent world: The specific questions of marine population genetics. Curr Zool 62:545-550. doi: 10.1093/cz/zow107

Bierne N, Roze D, Welch JJ (2013) Pervasive selection or is it ...? why are FST outliers sometimes so frequent? Mol Ecol 33:2061-2064. doi: 10.1111/mec.12241

Bik HM, Porazinska DL, Creer S, et al (2012) Sequencing our way towards understanding global eukaryotic biodiversity. Trends Ecol Evol 27:233-243. doi: 10.1016/j.tree.2011.11.010 
Biscontin A, Frigato E, Sales G, et al (2016) The opsin repertoire of the Antarctic krill Euphausia superba. Mar Genomics 29:61-68. doi: 10.1016/j.margen.2016.04.010

Black WC, Baer CF, Antolin MF, DuTeau NM (2001) Population genomics: genome-wide sampling of insect populations. Annu Rev Entomol 46:441-469. doi: 10.1146/annurev.ento.46.1.441

Blanco-Bercial L, Álvarez-Marqués F, Bucklin A (2011a) Comparative phylogeography and connectivity of sibling species of the marine copepod Clausocalanus (Calanoida). J Exp Mar Bio Ecol 404:108-115. doi: 10.1016/j.jembe.2011.05.011

Blanco-Bercial L, Álvarez-Marqués F, Bucklin A (2011b) Comparative phylogeography and connectivity of sibling species of the marine copepod Clausocalanus (Calanoida). J Exp Mar Bio Ecol 404:108-115. doi: 10.1016/j.jembe.2011.05.011

Blanco-Bercial L, Bucklin A (2016) New view of population genetics of zooplankton: RAD-seq analysis reveals population structure of the North Atlantic planktonic copepod Centropages typicus. Mol Ecol 25:1566-1580. doi: 10.1111/mec.13581

Blanco-Bercial L, Cornils A, Copley N, Bucklin A (2014) DNA Barcoding of marine copepods: assessment of analytical approaches to species identification. PLoS Curr 1-40. doi: 10.1371/currents.tol.cdf8b74881f87e3b01d56b43791626d2

Bolte S, Fuentes V, Haslob H, et al (2013) Population genetics of the invasive ctenophore Mnemiopsis leidyi in Europe reveal source-sink dynamics and secondary dispersal to the Mediterranean Sea. Mar Ecol Prog Ser 485:25-36. doi: 10.3354/meps10321

Bortolotto E, Bucklin A, Mezzavilla M, et al (2011) Gone with the currents: lack of genetic differentiation at the circum-continental scale in the Antarctic krill Euphausia superba. BMC Genet 12:32. doi: 10.1186/1471-2156-12-32

Brekhman V, Malik A, Haas B, et al (2015) Transcriptome profiling of the dynamic life cycle of the scypohozoan jellyfish Aurelia aurita. BMC Genomics 16:74. doi: 10.1186/s12864-015-1320-z

Bron JE, Frisch D, Goetze E, et al (2011) Observing copepods through a genomic lens. Front Zool 8:22. 
doi: 10.1186/1742-9994-8-22

Bucklin A, Hopcroft RR, Kosobokova KN, et al (2010a) DNA barcoding of Arctic Ocean holozooplankton for species identification and recognition. Deep Res Part II Top Stud Oceanogr 57:40-48. doi: 10.1016/j.dsr2.2009.08.005

Bucklin A, Kaartvedt S (2000) Population genetics of drifting (Calanus spp.) and resident (Acartia clausi) plankton in Norwegian fjords. J Plankton Res 22:1237-1251. doi:

10.1093/plankt/22.7.1237

Bucklin A, Lindeque PK, Rodriguez-Ezpeleta N, et al (2016) Metabarcoding of marine zooplankton: prospects, progress and pitfalls. J Plankton Res 38:393-400. doi: 10.1093/plankt/fbw023

Bucklin A, Ortman BD, Jennings RM, et al (2010b) A “Rosetta Stone” for metazoan zooplankton: DNA barcode analysis of species diversity of the Sargasso Sea (Northwest Atlantic Ocean). Deep Res Part II Top Stud Oceanogr 57:2234-2247. doi: 10.1016/j.dsr2.2010.09.025

Bucklin A, Smolenack SB, Bentley AM, Wiebe PH (1997) Gene flow patterns of the euphausiid, Meganyctiphanes norvegica, in the NW Atlantic based on mtDNA sequences for cytochrome b and cytochrome oxidase I. J Plankton Res 19:1763-1781. doi: 10.1093/plankt/19.11.1763

Bucklin A, Steinke D, Blanco-Bercial L (2011) DNA barcoding of marine metazoa. Ann Rev Mar Sci 3:471-508. doi: 10.1146/annurev-marine-120308-080950

Bucklin A, Sundt RC, Dahle G (1996) The population genetics of Calanus finmarchicus in the North Atlantic. Ophelia 44:29-45.

Bucklin A, Wiebe PH, Smolenack SB, et al (2007) DNA barcodes for species identification of euphausiids (Euphausiacea, Crustacea). J Plankton Res 29:483-493. doi: 10.1093/plankt/fbm031

Burton RS, Byrne RJ, Rawson PD (2007) Three divergent mitochondrial genomes from California populations of the copepod Tigriopus californicus. Gene 403:53-59. doi:

10.1016/j.gene.2007.07.026

Burton RS, Pereira RJ, Barreto FS (2013) Cytonuclear genomic interactions and hybrid breakdown. Annu Population Genomics of Marine Zooplankton - Bucklin et al. - August 22, 2017 Page 44 
Rev Ecol Evol Syst 44:281-302. doi: 10.1146/annurev-ecolsys-110512-135758

Bybee SM, Bracken-Grissom HD, Hermansen RA, et al (2011) Directed next generation sequencing for phylogenetics: An example using Decapoda (Crustacea). Zool Anz 250:497-506. doi:

10.1016/j.jcz.2011.05.010

Carlotti F, Bonnet D, Halsband-Lenk C (2007) Development and growth rates of Centropages typicus. Prog Oceanogr 72:164-194. doi: 10.1016/j.pocean.2007.01.011

Castellani C, Lindley AJ, Wootton M, et al (2012) Morphological and genetic variation in the North Atlantic copepod, Centropages typicus. J Mar Biol Assoc United Kingdom 92:99-106. doi: $10.1017 / \mathrm{S} 0025315411000932$

Caudill CC, Bucklin A (2004) Molecular phylogeography and evolutionary history of the estuarine copepod, Acartia tonsa, on the Northwest Atlantic coast. Hydrobiologia 511:91-102. doi: 10.1023/B:HYDR.0000014032.05680.9d

Chen G, Hare MP (2008) Cryptic ecological diversification of a planktonic estuarine copepod, Acartia tonsa. Mol Ecol 17:1451-1468. doi: 10.1111/j.1365-294X.2007.03657.x

Chen G, Hare MP (2011) Cryptic diversity and comparative phylogeography of the estuarine copepod Acartia tonsa on the US Atlantic coast. Mol Ecol 20:2425-2441. doi: 10.1111/j.1365294X.2011.05079.X

Choquet M, Alves Monteiro HJ, Bengtsson-Palme J, Hoarau G (2017a) The complete mitochondrial genome of the copepod Calanus glacialis. Mitochondrial DNA Part B 2:506-507. doi: $10.1080 / 23802359.2017 .1361357$

Choquet M, Smolina I, Soreide JE, Hoarau G (2017b) New insight on the population structure of Calanus finmarchicus in the North Atlantic using next-generation sequencing technologies. In: 13th International Conference on Copepoda. Los Angeles, CA, USA,

Chust G, Villarino E, Chenuil A, et al (2016) Dispersal similarly shapes both population genetics and community patterns in the marine realm. Sci Rep 6:28730. doi: 10.1038/srep28730 
Clark MS, Thorne MAS, Toullec JY, et al (2011) Antarctic krill 454 pyrosequencing reveals chaperone and stress transcriptome. PLoS One 6:1-17. doi: 10.1371/journal.pone.0015919

Cornils A, Wend-Heckmann B, Held C (2017) Global phylogeography of Oithona similis s.l. (Crustacea, Copepoda, Oithonidae) - A cosmopolitan plankton species or a complex of cryptic lineages? Mol Phylogenet Evol 107:473-485. doi: 10.1016/j.ympev.2016.12.019

Cowen RK, Sponaugle S (2009) Larval Dispersal and Marine Population Connectivity. Annu Rev Mar Sci 1:443-66. doi: 10.1146/annurev.marine.010908.163757

Crawford DL, Oleksiak MF (2016) Ecological population genomics in the marine environment. Brief Funct Genomics 15:342-351. doi: 10.1093/bfgp/elw008

Cristescu ME (2015) Genetic reconstructions of invasion history. Mol Ecol 24:2212-2225. doi: 10.1111/mec.13117

Davey JL, Blaxter MW (2010) RADseq: Next-generation population genetics. Brief Funct Genomics 9:416-423. doi: 10.1093/bfgp/elq031

Dawson MN, Cieciel K, Decker MB, et al (2015) Population-level perspectives on global change: genetic and demographic analyses indicate various scales, timing, and causes of scyphozoan jellyfish blooms. Biol Invasions 17:851-867. doi: 10.1007/s10530-014-0732-z

Deagle BE, Faux C, Kawaguchi S, et al (2015) Antarctic krill population genomics: Apparent panmixia, but genome complexity and large population size muddy the water. Mol Ecol 24:4943-4959. doi: 10.1111/mec.13370

De Pittà C, Biscontin A, Albiero A, et al (2013) The Antarctic Krill Euphausia superba Shows Diurnal Cycles of Transcription under Natural Conditions. PLoS One. doi: 10.1371/journal.pone.0068652 de Vargas C, Audic S, Henry N, et al (2015) Eukaryotic plankton diversity in the sunlit ocean. Science 348:1261605. doi: 10.1126/science.1261605

De Wit P, Dupont S, Thor P (2016) Selection on oxidative phosphorylation and ribosomal structure as a multigenerational response to ocean acidification in the common copepod Pseudocalanus 
acuspes. Evol Appl 9:1112-1123. doi: 10.1111/eva.12335

De Wit P, Pespeni MH, Palumbi SR (2015) SNP genotyping and population genomics from expressed sequences - Current advances and future possibilities. Mol Ecol 24:2310-2323. doi: 10.1111/mec.13165

Denoeud F, Henriet S, Mungpakdee S (2010) Plasticity of animal genome architecture unmasked by rapid evolution of a pelagic tunicate. Science (80- ) 1381-1386.

deYoung B, Barange M, Beaugrand G, et al (2008) Regime shifts in marine ecosystems: detection, prediction and management. Trends Ecol Evol 23:402-409. doi: 10.1016/j.tree.2008.03.008

Drillet G, Goetze E, Jepsen PM, et al (2008) Strain-specific vital rates in four Acartia tonsa cultures, I: Strain origin, genetic differentiation and egg survivorship. Aquaculture 280:109-116. doi: 10.1016/j.aquaculture.2008.04.005

Dufresne F, Jeffery N (2011) A guided tour of large genome size in animals: What we know and where we are heading. Chromosom Res 19:925-938. doi: 10.1007/s10577-011-9248-x

Edmands S (2001) Phylogeography of the intertidal copepod Tigriopus californicus reveals substantially reduced population differentiation at northern latitudes. Mol Ecol 10:1743-1750. doi: 10.1046/j.0962-1083.2001.01306.x

Ekblom R, Galindo J (2011) Applications of next generation sequencing in molecular ecology of nonmodel organisms. Heredity (Edinb) 107:1-15. doi: 10.1038/hdy.2010.152

Ellegren H (2014) Genome sequencing and population genomics in non-model organisms. Trends Ecol Evol 29:51-63. doi: 10.1016/j.tree.2013.09.008

Elliott TA, Gregory TR (2015) What's in a genome? The C-value enigma and the evolution of eukaryotic genome content. Philos Trans R Soc London Ser B-Biological Sci 370:20140331. doi: 10.1098/rstb.2014.0331

Elshire RJ, Glaubitz JC, Sun Q, et al (2011) A robust, simple genotyping-by-sequencing (GBS) approach for high diversity species. PLoS One 6:1-10. doi: 10.1371/journal.pone.0019379 
Escribano R, McLaren IA, Breteler WCMK (1992) Innate and acquired variation of nuclear DNA contents of marine copepods. Genome 35:602-610. doi: 10.1139/g92-090

Excoffier L, Lischer HEL (2010) Arlequin suite ver 3.5: A new series of programs to perform population genetics analyses under Linux and Windows. Mol Ecol Resour 10:564-567. doi: 10.1111/j.17550998.2010.02847.x

Excoffier L, Smouse PE, Quattro JM (1992) Analysis of molecular variance inferred from metric distances among DNA haplotypes: Application to human mitochondrial DNA restriction data. Genetics 131:479-491. doi: 10.1007/s00424-009-0730-7

Eyun S, Young Soh H, Posavi M, et al (2017) Evolutionary History of Chemosensory-Related Gene Families Across the Arthropoda. Mol Biol Evol 34:1838-1862. doi: 10.1093/molbev/msx147

Falk-Petersen S, Pavlov V, Timofeev S, Sargent J (2007) Climate variability and possible effects on Arctic food chains: the role of Calanus. In: Arctic Apline ecosystems and People in a Changing Environment. Springer Berlin Heidelberg, pp 147-166

Faure E, Casanova JP (2006) Comparison of chaetognath mitochondrial genomes and phylogenetical implications. Mitochondrion 6:258-262. doi: 10.1016/j.mito.2006.07.004

Foley BR, Rose CG, Rundle DE, et al (2011) A gene-based SNP resource and linkage map for the copepod Tigriopus californicus. BMC Genomics 12:568. doi: 10.1186/1471-2164-12-568

Foll M, Gaggiotti O (2008) A genome-scan method to identify selected loci appropriate for both dominant and codominant markers: A Bayesian perspective. Genetics 180:977-993. doi: 10.1534/genetics.108.092221

Francisco SM, Robalo JI, Levy A, Almada VC (2014) In Search of Phylogeographic Patterns in the Northeastern Atlantic and Adjacent Seas. In: Evolutionary Biology: Genome Evolution, Speciation, Coevolutions and Origin of Life. Springer Publishing, pp 323-338

Gagnaire PA, Broquet T, Aurelle D, et al (2015) Using neutral, selected, and hitchhiker loci to assess connectivity of marine populations in the genomic era. Evol Appl 8:769-786. doi: 
10.1111/eva.12288

Gagnaire PA, Gaggiotti OE (2016) Detecting polygenic selection in marine populations by combining population genomics and quantitative genetics approaches. Curr Zool 62:603-616. doi:

\subsection{3/cz/zow088}

Galindo HM, Pfeiffer-Herbert AS, McManus MA, et al (2010) Seascape genetics along a steep cline: Using genetic patterns to test predictions of marine larval dispersal. Mol Ecol 19:3692-3707. doi: 10.1111/j.1365-294X.2010.04694.X

Gayral P, Melo-Ferreira J, Glémin S, et al (2013) Reference-Free Population Genomics from NextGeneration Transcriptome Data and the Vertebrate-Invertebrate Gap. PLoS Genet. doi: 10.1371/journal.pgen.1003457

Genome 10K Community of Scientists (2009) Genome 10K: A proposal to obtain whole-genome sequence for 10000 vertebrate species. J Hered 100:659-674. doi: 10.1093/jhered/esp086

GIGA Community of Scientists (2014) The Global Invertebrate Genomics Alliance (GIGA): Developing Community Resources to Study Diverse Invertebrate Genomes. J Hered 105:1-18. doi: 10.1093/jhered/est084

Goetze E (2005) Global population genetic structure and biogeography of the oceanic copepods Eucalanus hyalinus and E. spinifer. Evolution 59:2378-2398. doi: 10.1554/05-077.1

Goetze E, Andrews KR, Peijnenburg KTCA, et al (2015) Temporal stability of genetic structure in a mesopelagic copepod. PLoS One 10:1-16. doi: 10.1371/journal.pone.0136087

Goetze E, Ohman MD (2010) Integrated molecular and morphological biogeography of the calanoid copepod family Eucalanidae. Deep Res Part II Top Stud Oceanogr 57:2110-2129. doi: 10.1016/j.dsr2.2010.09.014

Gregory TR (2017) Animal Genome Size Databse. http://www.genomesize.com. Accessed 20 Jun 2017

Gregory TR, Hebert PDN (1999) The modulation of DNA content: Proximate causes and ultimate consequences. Genome Res 9:317-324. doi: 10.1101/gr.9.4.317 
Gregory TR, Hebert PDN, Kolasa J (2000) Evolutionary implications of the relationship between genome size and body size in flatworms and copepods. Heredity (Edinb) 84:201-208. doi: 10.1046/j.1365-2540.2000.00661.x

Hahn C, Bachmann L, Chevreux B (2013) Reconstructing mitochondrial genomes directly from genomic next-generation sequencing reads - A baiting and iterative mapping approach. Nucleic Acids Res. doi: 10.1093/nar/gkt371

Hansen MM, Hemmer-Hansen J (2007) Landscape genetics goes to sea. J Biol 6:6. doi: 10.1186/jbiol59

Havird JC, Santos SR (2016) Here we are, but where do we go? A systematic review of crustacean transcriptomic studies from 2014-2015. Integr Comp Biol 56:1055-1066. doi: 10.1093/icb/icw061

Head EJH, Harris LR, Yashayaev I (2003) Distributions of Calanus spp. and other mesozooplankton in the Labrador Sea in relation to hydrography in spring and summer (1995-2000). Prog Oceanogr 59:1-30. doi: 10.1016/S0079-6611(03)00111-3

Hedrick PW (2006) Genetic polymorphism in heterogeneous environments: The age of genomics. Annu Rev Ecol Evol Syst 37:67-93. doi: 10.1146/annurev.ecolsys.37.091305.110132

Helfenbein KG, Fourcade HM, Vanjani RG, Boore JL (2004) The mitochondrial genome of Paraspadella gotoi is highly reduced and reveals that chaetognaths are a sister group to protostomes. Proc Natl Acad Sci U S A 101:10639-10643. doi: 10.1073/pnas.0400941101

Hellberg ME (2009) Gene Flow and Isolation among Populations of Marine Animals. Annu Rev Ecol Evol Syst 40:291-310. doi: DOI 10.1146/annurev.ecolsys.110308.120223

Helyar SJ, Hemmer-Hansen J, Bekkevold D, et al (2011) Application of SNPs for population genetics of nonmodel organisms: New opportunities and challenges. Mol Ecol Resour 11:123-136. doi: 10.1111/j.1755-0998.2010.02943.x

Hemmer-Hansen J, Overgaard N, Hemmer-Hansen J, et al (2014) Population genomics of marine fishes: next generation prospects and challenges Population Genomics of Marine Fishes: Next- 
Generation Prospects and Challenges. Biol Bull 227:117-132. doi: 10.1086/BBLv227n2p117

Hessen DO, Persson J (2009) Genome size as a determinant of growth and life-history traits in crustaceans. Biol J Linn Soc 98:393-399. doi: 10.1111/j.1095-8312.2009.01285.x

Hirai J, Tsuda A (2015) Metagenetic community analysis of epipelagic planktonic copepods in the tropical and subtropical pacific. Mar Ecol Prog Ser 534:65-78. doi: 10.3354/meps11404

Hirai J, Tsuda A, Goetze E (2015) Extensive genetic diversity and endemism across the global range of the oceanic copepod Pleuromamma abdominalis. Prog Oceanogr 138:77-90. doi: 10.1016/j.pocean.2015.09.002

Hodges E, Xuan Z, Balija V, et al (2007) Genome-wide in situ exon capture for selective resequencing. Nat Genet 39:1522-7. doi: 10.1038/ng.2007.42

Hwang D-S, Park E, Won Y-J, et al (2014) Complete mitochondrial genome of the jellyfish, Chrysaora quinquecirrha (Cnidaria, Scyphozoa). Mitochondrial DNA 25:25-26. doi: $10.3109 / 19401736.2013 .775272$

i5K Consortium (2013) The i5K initiative: Advancing arthropod genomics for knowledge, human health, agriculture, and the environment. J Hered 104:595-600. doi: 10.1093/jhered/est050

Iacchei M, Butcher E, Portner E, Goetze E (2017) It's about time: Insights into temporal genetic patterns in oceanic zooplankton from biodiversity indices. Limnol Oceanogr. doi: 10.1002/lno.10538 Jarman SN, Deagle BE (2016) Genetics of Antarctic krill. In: Siegel V (ed) Biology and Ecology of Antarctic Krill. Advances in Polar Ecology, pp 247-277

Jeffery NW (2012) The first genome size estimates for six species of krill (Malacostraca, Euphausiidae): Large genomes at the north and south poles. Polar Biol 35:959-962. doi: 10.1007/s00300-011$1137-4$

Jeffery NW, Ellis EA, Oakley TH, Gregory TR (2017) The Genome Sizes of Ostracod Crustaceans Correlate with Body Size and Evolutionary History, but not Environment. J Hered 108:701-706. doi: 10.1093/jhered/esx055 
Jeffrey NW (2015) Genome Size Diversity and Evolution in the Crustacea. University of Guelph, Canada Jepsen PM, Bjørbæk NS, Rayner TA, et al (2017) Recommended feeding regime and light climate in live feed cultures of the calanoid copepod Acartia tonsa Dana. Aquac Int 25:635-654. doi: 10.1007/s10499-016-0063-4

Johnson KM, Hofmann GE (2016) A transcriptome resource for the Antarctic pteropod Limacina helicina antarctica. Mar Genomics 28:25-28. doi: 10.1016/j.margen.2016.04.002

Jones MR, Good JM (2016) Targeted capture in evolutionary and ecological genomics. Mol Ecol 25:185202. doi: $10.1111 /$ mec.13304

Jue NK, Batta-Lona PG, Trusiak S, et al (2016) Rapid evolutionary rates and unique genomic signatures discovered in the first reference genome for the southern ocean salp, salpa thompsoni (Urochordata, Thaliacea). Genome Biol Evol 8:3171-3186. doi: 10.1093/gbe/evw215

Jung SO, Lee YM, Park TJ, et al (2006) The complete mitochondrial genome of the intertidal copepod Tigriopus sp. (Copepoda, Harpactidae) from Korea and phylogenetic considerations. J Exp Mar Bio Ecol 333:251-262. doi: 10.1016/j.jembe.2005.12.047

Kang S, Ahn D, Lee JH, et al (2017) The genome of the Antarctic-endemic copepod, Tigriopus kingsejongensis. Gigascience 1-9. doi: 10.1093/gigascience/giw010

Ki JS, Hop H, Kim SJ, et al (2010) Complete mitochondrial genome sequence of the Arctic gammarid, Onisimus nanseni (Crustacea; Amphipoda): Novel gene structures and unusual control region features. Comp Biochem Physiol - Part D Genomics Proteomics 5:105-115. doi: 10.1016/j.cbd.2010.02.002

Ki JS, Lee KW, Park HG, et al (2009) Phylogeography of the copepod Tigriopus japonicus along the Northwest Pacific rim. J Plankton Res 31:209-221. doi: 10.1093/plankt/fbn100

Kim HS, Lee BY, Won EJ, et al (2015) Identification of xenobiotic biodegradation and metabolismrelated genes in the copepod Tigriopus japonicus whole transcriptome analysis. Mar Genomics 24:207-208. doi: 10.1016/j.margen.2015.05.011 
Kim S, Kim J, Choi H-G, et al (2012) Complete mitochondrial genome of the northern mauxia shrimp Acetes chinensis (Decapoda, Dendrobranchiata, Sergestoidae). Mitochondrial DNA 23:28-30. doi: 10.3109/19401736.2011.643878

Kim S, Lim BJ, Min GS, Choi HG (2013) The complete mitochondrial genome of Arctic Calanus hyperboreus (Copepoda, Calanoida) reveals characteristic patterns in calanoid mitochondrial genome. Gene 520:64-72. doi: 10.1016/j.gene.2012.09.059

Knowles LL (2009) Statistical Phylogeography. Annu Rev Ecol Evol Syst 40:593-612. doi: 10.1146/annurev.ecolsys.38.091206.095702

Koh HY, Lee JH, Han SJ, et al (2015) A transcriptomic analysis of the response of the arctic pteropod Limacina helicina to carbon dioxide-driven seawater acidification. Polar Biol 38:1727-1740. doi: 10.1007/s00300-015-1738-4

Kohn AB, Citarella MR, Kocot KM, et al (2012) Rapid evolution of the compact and unusual mitochondrial genome in the ctenophore, Pleurobrachia bachei. Mol Phylogenet Evol 63:203207. doi: 10.1016/j.ympev.2011.12.009

Kollias S, Poortvliet M, Smolina I, Hoarau G (2015) Low cost sequencing of mitogenomes from museum samples using baits capture and Ion Torrent. Conserv Genet Resour 7:345-348. doi: 10.1007/s12686-015-0433-7

Kool JT, Moilanen A, Treml EA (2013) Population connectivity: Recent advances and new perspectives. Landsc Ecol 28:165-185. doi: 10.1007/s10980-012-9819-z

Kulagin DN, Stupnikova AN, Neretina T V., Mugue NS (2014) Spatial genetic heterogeneity of the cosmopolitan chaetognath Eukrohnia hamata (Möbius, 1875) revealed by mitochondrial DNA. Hydrobiologia 721:197-207. doi: 10.1007/s10750-013-1661-z

Kuriyama M, Nishida S (2006) Species diversity and niche-partitioning in the pelagic copepods of the family Scolecitrichidae ( Calanoida). Crustaceanna 79:293-317.

Laakmann S, Auel H, Kochzius M (2012) Evolution in the deep sea: Biological traits, ecology and Population Genomics of Marine Zooplankton - Bucklin et al. - August 22, 2017

Page 53 
phylogenetics of pelagic copepods. Mol Phylogenet Evol 65:535-546. doi:

10.1016/j.ympev.2012.07.007

Lauritano C, Procaccini G, Ianora A (2012) Gene expression patterns and stress response in marine copepods. Mar Environ Res 76:22-31. doi: 10.1016/j.marenvres.2011.09.015

Lechner M, Marz M, Ihling C, et al (2013) The correlation of genome size and DNA methylation rate in metazoans. Theory Biosci 132:47-60. doi: 10.1007/s12064-012-0167-y

Lee BY, Kim HS, Choi BS, et al (2015) RNA-seq based whole transcriptome analysis of the cyclopoid copepod Paracyclopina nana focusing on xenobiotics metabolism. Comp Biochem Physiol - Part D Genomics Proteomics 15:12-19. doi: 10.1016/j.cbd.2015.04.002

Lee CE (2000) Global phylogeography of a cryptic copepod species complex and reproductive isolation between genetically proximate “populations”. Evolution 54:2014-2027. doi: 10.1111/j.00143820.2000.tb01245.x

Lee CE (2016) Evolutionary mechanisms of habitat invasions, using the copepod Eurytemora affinis as a model system. Evol Appl 9:248-270. doi: 10.1111/eva.12334

Leinaas HP, Jalal M, Gabrielsen TM, Hessen DO (2016) Inter- and intraspecific variation in body- and genome size in calanoid copepods from temperate and arctic waters. Ecol Evol 6:5585-5595. doi: 10.1002/ece3.2302

Lenz PH, Roncalli V, Hassett RP, et al (2014) De novo assembly of a transcriptome for Calanus finmarchicus (crustacea, copepoda) - The dominant zooplankter of the North Atlantic Ocean. PLoS One. doi: 10.1371/journal.pone.0088589

Leray M, Knowlton N (2016) Censusing marine eukaryotic diversity in the twenty-first century. Philos Trans R Soc London Ser B, Biol Sci R Soc London Ser B-Biological Sci 371:1-9. doi: $10.1098 /$ rstb.2015.0331

Levasseur A, Orlando L, Bailly X, et al (2007) Conceptual bases for quantifying the role of the environment on gene evolution: The participation of positive selection and neutral evolution. Biol 
Rev 82:551-572. doi: 10.1111/j.1469-185X.2007.00024.X

Levin SA, Segel LA (1976) Hypothesis for origin of planktonic patchiness. Nature 259:659-659. doi: 10.1038/259659a0

Li F, Ma L, Zhang H, et al (2017) A thioredoxin from Antarctic microcrustacean (Euphausia superba): Cloning and functional characterization. Fish Shellfish Immunol 63:376-383. doi: 10.1016/j.fsi.2017.02.035

Li P, Yang M, Ni S, et al (2016) Complete mitochondrial genome sequence of the pelagic chaetognath, Sagitta ferox. Mitochondrial DNA 1736:1-2. doi: 10.3109/19401736.2015.1106508

Lima TG, Willett CS (2017) Locally adapted populations of a copepod can evolve different gene expression patterns under the same environmental pressures. Ecol Evol 7:4312-4325. doi: 10.1002/ece3.3016

Lindeque PK, Parry HE, Harmer RA, et al (2013) Next generation sequencing reveals the hidden diversity of zooplankton assemblages. PLoS One 8:1-14. doi: 10.1371/journal.pone.0081327

Longhurst AR (2007) Ecological Geography of the Sea. Elsevier Inc.

Luikart G, England PR, Tallmon D, et al (2003) The power and promise of population genomics: from genotyping to genome typing. Nat Rev Genet 4:981-994. doi: 10.1038/nrg1226

Maas AE, Blanco-Bercial L (2016) Meganyctiphanes norvegica Transcriptome and Gene expression, GenBank Direct Accession No. PRJNA324094 ID:324094. https://www.ncbi.nlm.nih.gov/bioproject/?term=Meganyctiphanes norvegica.

Maas AE, Lawson GL, Tarrant AM (2015) Transcriptome-wide analysis of the response of the thecosome pteropod Clio pyramidata to short-term $\mathrm{CO}_{2}$ exposure. Comp Biochem Physiol - Part D Genomics Proteomics 16:1-9. doi: 10.1016/j.cbd.2015.06.002

Machida RJ, Miya MU, Nishida M, Nishida S (2002) Complete mitochondrial DNA sequence of Tigriopus japonicus (Crustacea: Copepoda). Mar Biotechnol 4:406-417. doi: 10.1007/s10126002-0033-X 
Madoui M-A, Poulain J, Sugier K, et al (2017) New insights into global biogeography, population structure and natural selection from the genome of the epipelagic copepod Oithona. Mol Ecol 38:42-49. doi: 10.1111/mec.14214

Maricic T, Whitten M, Pääbo S (2010) Multiplexed DNA sequence capture of mitochondrial genomes using PCR products. PLoS One 5:9-13. doi: 10.1371/journal.pone.0014004

Marlétaz F, Parco Y., Shenglin L, Peijnenburg KTCA (2017) Extreme Mitogenomic Variation in Natural Populations of Chaetognaths. Genome Biol Evol 9:1-21. doi: 10.1093/gbe/evx090

McGovern TM, Keever CC, Saski CA, et al (2010) Divergence genetics analysis reveals historical population genetic processes leading to contrasting phylogeographic patterns in co-distributed species. Mol Ecol 19:5043-5060. doi: 10.1111/j.1365-294X.2010.04854.X

McLaren I a, Laberge E, Corkett CJ, Sevigny J-M (1989) Life cycles of four species of Pseudocalanus in Nova Scotia. Can J Zool 67:552-558. doi: doi:10.1139/z89-078

McLaren IA, Sevigny J-M, Corkett CJ (1988) Body sizes, development rates, and genome sizes among Calanus species. Hydrobiologia 167/168:275-284.

Meyer B, Martini P, Biscontin A, et al (2015) Pyrosequencing and de novo assembly of Antarctic krill (Euphausia superba) transcriptome to study the adaptability of krill to climate-induced environmental changes. Mol Ecol Resour 15:1460-1471. doi: 10.1111/1755-0998.12408

Miller B, von der Heyden S, Gibbons M (2012) Significant population genetic structuring of the holoplanktic scyphozoan Pelagia noctiluca in the Atlantic Ocean. African J Mar Sci 34:425-430. doi: 10.2989/1814232X.2012.726646

Milligan PJ, Stahl EA, Schizas N V., Turner JT (2011) Phylogeography of the copepod Acartia hudsonica in estuaries of the northeastern United States. Hydrobiologia 666:155-165. doi: 10.1007/s10750010-0097-y

Minxiao W, Song S, Chaolun L, Xin S (2011) Distinctive mitochondrial genome of Calanoid copepod Calanus sinicus with multiple large non-coding regions and reshuffled gene order: useful 
molecular markers for phylogenetic and population studies. BMC Genomics 12:73. doi: $10.1186 / 1471-2164-12-73$

Miyamoto H, Machida RJ, Nishida S (2010) Genetic diversity and cryptic speciation of the deep sea chaetognath Caecosagitta macrocephala (Fowler, 1904). Deep Res Part II Top Stud Oceanogr 57:2211-2219. doi: 10.1016/j.dsr2.2010.09.023

Miyamoto H, Machida RJ, Nishida S (2012) Global phylogeography of the deep-sea pelagic chaetognath Eukrohnia hamata. Prog Oceanogr 104:99-109. doi: 10.1016/j.pocean.2012.06.003

Moroz LL, Kocot KM, Citarella MR, et al (2014) The Ctenophore Genome and the Evolutionary Origins of Neutral Systems. Nature 510:109-114. doi: 10.1038/nature13400

Narum SR, Buerkle CA, Davey JW, et al (2013) Genotyping-by-sequencing in ecological and conservation genomics. Mol Ecol 22:2841-2847. doi: 10.1111/mec.12350

Nielsen EE, Hemmer-Hansen J, Larsen PF, Bekkevold D (2009) Population genomics of marine fishes: Identifying adaptive variation in space and time. Mol Ecol 18:3128-3150. doi: 10.1111/j.1365294X.2009.04272.x

Nilsson B, Jepsen PM, Rewitz K, Hansen BW (2014) Expression of hsp70 and ferritin in embryos of the copepod Acartia tonsa (Dana) during transition between subitaneous and quiescent state. J Plankton Res 36:513-522. doi: 10.1093/plankt/fbt099

Norton EL, Goetze E (2013) Equatorial dispersal barriers and limited population connectivity among oceans in a planktonic copepod. Limnol Oceanogr 58:1581-1596. doi: 10.4319/lo.2013.58.5.1581

O’Grady JF, Hoelters LS, Swain MT, Wilcockson DC (2016) Identification and temporal expression of putative circadian clock transcripts in the amphipod crustacean Talitrus saltator. PeerJ 4:e2555. doi: 10.7717/peerj.2555

Ogoh K, Ohmiya Y (2004) Complete mitochondrial DNA sequence of the sea-firefly, Vargula hilgendorfii (Crustacea, Ostracoda) with duplicate control regions. Gene 327:131-139. doi: 10.1016/j.gene.2003.11.011 
Omori M, Hamner WM (1982) Patchy distribution of zooplankton: Behavior, population assessment and sampling problems. Mar Biol 72:193-200. doi: 10.1007/BF00396920

Papadopoulos LN, Peijnenburg KTCA, Luttikhuizen PC (2005) Phylogeography of the calanoid copepods Calanus helgolandicus and C. euxinus suggests Pleistocene divergences between Atlantic, Mediterranean, and Black Sea populations. Mar Biol 147:1353-1365. doi: 10.1007/s00227-0050038-x

Papetti C, Zane L, Bortolotto E, et al (2005) Genetic differentiation and local temporal stability of population structure in the euphausiid Meganyctiphanes norvegica. Mar Ecol Prog Ser 289:225235. doi: $10.3354 /$ meps289225

Papillon D, Perez Y, Caubit X, Le Parco Y (2004) Identification of Chaetognaths as protostomes is supported by the analysis of their mitochondrial genome. Mol Biol Evol 21:2122-2129. doi: 10.1093/molbev/msh229

Papot C, Cascella K, Toullec JY, Jollivet D (2016) Divergent ecological histories of two sister Antarctic krill species led to contrasted patterns of genetic diversity in their heat-shock protein (hsp70) arsenal. Ecol Evol 6:1555-1575. doi: 10.1002/ece3.1989

Patarnello T, Papetti C, Zane L (2010) Genetics of Northern Krill (Megantyctiphanes norvegica Sars). In: Tarling G (ed) Biology of Northern Krill. p Vol 57

Pearman JK, Irigoien X (2015) Assessment of zooplankton community composition along a depth profile in the central Red Sea. PLoS One 10:1-14. doi: 10.1371/journal.pone.0133487

Peijnenburg KTCA, Breeuwer JAJ, Pierrot-Bults AC, Menken SBJ (2004) Phylogeography of the planktonic chaetognath Sagitta setosa reveals isolation in European seas. Evolution 58:14721487. doi: 10.1554/03-638

Peijnenburg KTCA, Fauvelot C, Breeuwer JAJ, Menken SBJ (2006) Spatial and temporal genetic structure of the planktonic Sagitta setosa (Chaetognatha) in European seas as revealed by mitochondrial and nuclear DNA markers. Mol Ecol 15:3319-3338. doi: 10.1111/j.1365- 
294X.2006.03002.x

Peijnenburg KTCA, Goetze E (2013) High evolutionary potential of marine zooplankton. Ecol Evol 3:2765-2783. doi: 10.1002/ece3.644

Peijnenburg KTCA, Van Haastrecht EK, Fauvelot C (2005) Present-day genetic composition suggests contrasting demographic histories of two dominant chaetognaths of the North-East Atlantic, Sagitta elegans and S. setosa. Mar Biol 147:1279-1289. doi: 10.1007/s00227-005-0041-2

Pereira RJ, Barreto FS, Pierce NT, et al (2016) Transcriptome-wide patterns of divergence during allopatric evolution. Mol Ecol 25:1478-1493. doi: 10.1111/mec.13579

Pereira RJ, Sasaki MC, Burton RS (2017) Adaptation to a latitudinal thermal gradient within a widespread copepod species: the contributions of genetic divergence and phenotypic plasticity. Proc R Soc B Biol Sci 284:20170236. doi: 10.1098/rspb.2017.0236

Peterson BK, Weber JN, Kay EH, et al (2012) Double digest RADseq: An inexpensive method for de novo SNP discovery and genotyping in model and non-model species. PLoS One. doi: 10.1371/journal.pone.0037135

Petkeviciute E, Kania PW, Skovgaard A (2015) Genetic responses of the marine copepod Acartia tonsa (Dana) to heat shock and epibiont infestation. Aquac Reports 2:10-16. doi: 10.1016/j.aqrep.2015.04.001

Pett W, Ryan JF, Pang K, et al (2011) Extreme mitochondrial evolution in the ctenophore Mnemiopsis leidyi: Insight from mtDNA and the nuclear genome. Mitochondrial DNA 22:130-42. doi: $10.3109 / 19401736.2011 .624611$

Planque B, Graeme Hay IC, Ibanez F, Gamble JC (1997) Large scale spatial variations in the seasonal abundance of Calanus finmarchicus. Deep Res I 44:315-326.

Pogson GH (2016) Studying the genetic basis of speciation in high gene flow marine invertebrates. Curr Zool 62:643-653. doi: 10.1093/cz/zow093

Prokopowich CD, Gregory TR, Crease TJ (2003) The correlation between rDNA copy number and Population Genomics of Marine Zooplankton - Bucklin et al. - August 22, 2017

Page 59 
genome size in eukaryotes. Genome 46:48-50. doi: 10.1139/g02-103

Provan J, Beatty GE, Keating SL, et al (2009) High dispersal potential has maintained long-term population stability in the North Atlantic copepod Calanus finmarchicus. Proc Biol Sci 276:301307. doi: 10.1098/rspb.2008.1062

Questel JM, Blanco-Bercial L, Hopcroft RR, Bucklin A (2016) Phylogeography and connectivity of the Pseudocalanus (Copepoda: Calanoida) species complex in the eastern North Pacific and the Pacific Arctic Region. J Plankton Res 0:1-14. doi: 10.1093/plankt/fbw025

Rahlff J, Peters J, Moyano M, et al (2017) Short-term molecular and physiological responses to heat stress in neritic copepods Acartia tonsa and Eurytemora affinis. Comp Biochem Physiol -Part A Mol Integr Physiol 203:348-358. doi: 10.1016/j.cbpa.2016.11.001

Raisuddin S, Kwok KWH, Leung KMY, et al (2007) The copepod Tigriopus: A promising marine model organism for ecotoxicology and environmental genomics. Aquat Toxicol 83:161-173. doi: 10.1016/j.aquatox.2007.04.005

Ramos AA, Weydmann A, Cox CJ, et al (2015) A transcriptome resource for the copepod Calanus glacialis across a range of culture temperatures. Mar Genomics 23:27-29. doi: 10.1016/j.margen.2015.03.014

Rasch EM, Lee CE, Wyngaard GA (2004) DNA-Feulgen cytophotometric determination of genome size for the freshwater-invading copepod Eurytemora affinis. Genome 47:559-564. doi: 10.1139/G04014

Rawson PD, Brazeau D a, Burton RS (2000) Isolation and characterization of cytochrome c from the marine copepod Tigriopus californicus. Gene 248:15-22.

Reitzel AM, Herrera S, Layden MJ, et al (2013) Going where traditional markers have not gone before: Utility of and promise for RAD sequencing in marine invertebrate phylogeography and population genomics. Mol Ecol 22:2953-2970. doi: 10.1111/mec.12228

Renaut S, Dion-Co^té AM (2016) History repeats itself: Genomic divergence in copepods. Mol Ecol Population Genomics of Marine Zooplankton - Bucklin et al. - August 22, 2017 Page 60 
25:1417-1419. doi: 10.1111/mec.13577

Riginos C, Crandall ED, Liggins L, et al (2016) Navigating the currents of seascape genomics: How spatial analyses can augment population genomic studies. Curr Zool 62:581-601. doi:

\subsection{3/cz/zow067}

Romero IG, Ruvinsky I, Gilad Y (2014) Comparative studies of gene expression and the evolution of gene regulation. Nat Rev Genet 13:505-516. doi: 10.1038/nrg3229.Comparative

Roncalli V, Cieslak MC, Lenz PH (2016) Transcriptomic responses of the calanoid copepod Calanus finmarchicus to the saxitoxin producing dinoflagellate Alexandrium fundyense. Nat Publ Gr 1-13. doi: $10.1038 /$ srep25708

Ryan JF, Pang K, Schnitzler CE, et al (2013) The genome of the ctenophore Mnemiopsis leidyi and its implications for cell type evolution. Science (80- ) 342:1242592. doi: 10.1126/science.1242592

Saborowski R, Buchholz F (2002) Metabolic properties of Northern krill, Meganyctiphanes norvegica, from different climatic zones. I. Respiration and excretion. Mar Biol 140:547-556. doi:

$$
\text { 10.1007/s00227-001-0730-4 }
$$

Sales G, Deagle BE, Calura E, et al (2017) KrillDB: A de novo transcriptome database for the Antarctic krill (Euphausia superba). PLoS One 12:1-12. doi: 10.1371/journal.pone.0171908

Savolainen O, Lascoux M, Merilä J (2013) Ecological genomics of local adaptation. Nat Rev Genet 14:807-20. doi: 10.1038/nrg3522

Schindel DE, Miller SE (2005) DNA barcoding a useful tool for taxonomists. Naure 435:17-17.

Schlötterer C, Tobler R, Kofler R, Nolte V (2014) Sequencing pools of individuals — mining genomewide polymorphism data without big funding. Nat Rev Genet 15:749-763. doi: 10.1038/nrg3803

Schoville SD, Barreto FS, Moy GW, et al (2012) Investigating the molecular basis of local adaptation to thermal stress: population differences in gene expression across the transcriptome of the copepod Tigriopus californicus. BMC Evol Biol 12:170. doi: 10.1186/1471-2148-12-170

Schunter C, Carreras-Carbonell J, MacPherson E, et al (2011) Matching genetics with oceanography: 
Directional gene flow in a Mediterranean fish species. Mol Ecol 20:5167-5181. doi:

10.1111/j.1365-294X.2011.05355.x

Shao Z, Graf S, Chaga OY, Lavrov D V. (2006) Mitochondrial genome of the moon jelly Aurelia aurita (Cnidaria, Scyphozoa): A linear DNA molecule encoding a putative DNA-dependent DNA polymerase. Gene 381:92-101. doi: 10.1016/j.gene.2006.06.021

Shen X, Wang H, Ren J, et al (2010) The mitochondrial genome of Euphausia superba (Prydz Bay) (Crustacea: Malacostraca: Euphausiacea) reveals a novel gene arrangement and potential molecular markers. Mol Biol Rep 37:771-784. doi: 10.1007/s11033-009-9602-7

Shen X, Wang H, Wang M, Liu B (2011) The complete mitochondrial genome sequence of Euphausia pacifica (Malacostraca: Euphausiacea) reveals a novel gene order and unusual tandem repeats. Genome 54:911-22. doi: 10.1139/g11-053

Sherman CDH, Lotterhos KE, Richardson MF, et al (2016) What are we missing about marine invasions? Filling in the gaps with evolutionary genomics. Mar Biol 163:1-24. doi: 10.1007/s00227-0162961-4

Siegel V, Watkins JL (2016) Distribution, Biomass and Demography of Antarctic Krill, Euphausia superba. In: Volker S (ed) Biology and Ecology of Antarctic Krill. Springer International Publishing, pp 21-100

Skjoldal HR, Wiebe PH, Postel L, et al (2013) Intercomparison of zooplankton (net) sampling systems: Results from the ICES/GLOBEC sea-going workshop. Prog Oceanogr 108:1-42. doi: 10.1016/j.pocean.2012.10.006

Smolina I (2015) Calanus in the North Atlantic: species identification, stress response, and population genetic structure. PhD Aquat Biosci 15:64.

Smolina I, Harmer R, Lindeque P, Hoarau G (2016) Reduced up-regulation of gene expression in response to elevated temperatures in the mid-Atlantic population of Calanus finmarchicus. J Exp Mar Bio Ecol 485:88-93. doi: 10.1016/j.jembe.2016.09.003 
Smolina I, Kollias S, Møller E, et al (2015) Contrasting transcriptome response to thermal stress in two key zooplankton species, Calanus finmarchicus and C. glacialis. Mar Ecol Prog Ser 534:79-93. doi: $10.3354 /$ meps11398

Smolina I, Kollias S, Poortvliet M, et al (2014) Genome- and transcriptome-assisted development of nuclear insertion/deletion markers for Calanus species (Copepoda: Calanoida) identification. Mol Ecol Resour 14:1072-1079. doi: 10.1111/1755-0998.12241

Stapley J, Reger J, Feulner PGD, et al (2010) Adaptation genomics: The next generation. Trends Ecol Evol 25:705-712. doi: 10.1016/j.tree.2010.09.002

Stopar K, Ramšak A, Trontelj P, Malej A (2010) Lack of genetic structure in the jellyfish Pelagia noctiluca (Cnidaria: Scyphozoa: Semaeostomeae) across European seas. Mol Phylogenet Evol 57:417-428. doi: 10.1016/j.ympev.2010.07.004

Sun C, Wyngaard G, Walton DB, et al (2014) Billions of basepairs of recently expanded, repetitive sequences are eliminated from the somatic genome during copepod development. BMC Genomics 15:186. doi: 10.1186/1471-2164-15-186

Sun C, Zhao Y, Li H, et al (2015) Unreliable quantitation of species abundance based on high-throughput sequencing data of zooplankton communities. Aquat Biol 24:9-15. doi: 10.3354/ab00629

Tarrant AM, Baumgartner MF, Hansen BH, et al (2014) Transcriptional profiling of reproductive development, lipid storage and molting throughout the last juvenile stage of the marine copepod Calanus finmarchicus. Front Zool 11:91. doi: 10.1186/s12983-014-0091-8

Thabet AA, Maas AE, Saber SA, Tarrant AM (2017) Assembly of a reference transcriptome for the gymnosome pteropod Clione limacina and profiling responses to short-term $\mathrm{CO}_{2}$ exposure. Mar Genomics 34:39-45. doi: 10.1016/j.margen.2017.03.003

Toews DPL, Brelsford A (2012) The biogeography of mitochondrial and nuclear discordance in animals. Mol Ecol 21:3907-3930. doi: 10.1111/j.1365-294X.2012.05664.x

Toullec JY, Corre E, Bernay B, et al (2013) Transcriptome and Peptidome Characterisation of the Main Population Genomics of Marine Zooplankton - Bucklin et al. - August 22, $2017 \quad$ Page 63 
Neuropeptides and Peptidic Hormones of a Euphausiid: The Ice Krill, Euphausia crystallorophias. PLoS One. doi: 10.1371/journal.pone.0071609

Tsagkogeorga G, Cahais V, Galtier N (2012) The population genomics of a fast evolver: High levels of diversity, functional constraint, and molecular adaptation in the tunicate Ciona intestinalis. Genome Biol Evol 4:740-749. doi: 10.1093/gbe/evs054

Unal E, Bucklin A (2010) Basin-scale population genetic structure of the planktonic copepod Calanus finmarchicus in the North Atlantic Ocean. Prog Oceanogr 87:175-185. doi: 10.1016/j.pocean.2010.09.017

Voolstra CR, W??rheide G, Lopez J V. (2017) Advancing genomics through the Global Invertebrate Genomics Alliance (GIGA). Invertebr Syst 31:1-7. doi: 10.1071/IS16059

Wang K, Omotezako T, Kishi K, et al (2015) Maternal and zygotic transcriptomes in the appendicularian, Oikopleura dioica: novel protein-encoding genes, intra-species sequence variations, and transspliced RNA leader. Dev Genes Evol 225:149-159. doi: 10.1007/s00427-015-0502-7

Wang S, Meyer E, McKay JK, Matz M V (2012) 2b-RAD: a simple and flexible method for genome-wide genotyping. Nat Methods 9:808-810. doi: 10.1038/nmeth.2023

Waples RS (1998) Separating the wheat from the chaff: Patterns of genetic differentiation in high gene flow species. J Hered 89:438-450. doi: 10.1093/jhered/89.5.438

Waples RS, Punt AE, Cope JM (2008) Integrating genetic data into management of marine resources: How can we do it better? Fish Fish 9:423-449. doi: 10.1111/j.1467-2979.2008.00303.x

Weersing K, Toonen RJ (2009) Population genetics, larval dispersal, and connectivity in marine systems. Mar Ecol Prog Ser 393:1-12. doi: 10.3354/meps08287

Wei S, Li P, Yang M, et al (2016) The mitochondrial genome of the pelagic chaetognath, Pterosagitta draco. Mitochondrial DNA Part B 1:515-516. doi: 10.1080/23802359.2016.1197055

Whitehead A (2012) Comparative genomics in ecological physiology: toward a more nuanced understanding of acclimation and adaptation. J Exp Biol 215:884-891. doi: 10.1242/jeb.058735 
Wiebe PH, Harris RP, St. John MA, et al (2009) BASIN: Basin-scale Analysis, Synthesis, and INtegration. Science Plan and Implementation Strategy. GLOBEC Report 27: iii, 43pp.

Wiebe PH, Bucklin A, Madin L, et al (2010) Deep-sea sampling on CMarZ cruises in the Atlantic Ocean - an Introduction. Deep Res Part II Top Stud Oceanogr 57:2157-2166. doi:

10.1016/j.dsr2.2010.09.018

Wiebe PH, Lawson GL, Lavery AC, et al (2013) Improved agreement of net and acoustical methods for surveying euphausiids by mitigating avoidance using a net-based LED strobe light system. ICES J Mar Sci 70:650-664. doi: 10.1093/icesjms/fsr005

Wiebe PH (1968) Plankton patchiness: effects on repeated net tows. Limnol Oceanogr 13:315-321. doi: 10.4319/lo.1968.13.2.0315

Wyngaard GA, McLaren IA, White MM, Sévigny JM (1995) Unusually high numbers of ribosomal RNA genes in copepods (Arthropoda: Crustacea) and their relationship to genome size. Genome 38:97104. doi: 10.1139/g95-012

Wyngaard GA, Rasch EM (2000) Patterns of genome size in the copepoda. Hydrobiologia 417:43-56. doi: 10.1023/A:1003855322358

Wyngaard GA, Rasch EM, Connelly BA (2011) Unusual augmentation of germline genome size in Cyclops kolensis (Crustacea, Copepoda): Further evidence in support of a revised model of chromatin diminution. Chromosom Res 19:911-923. doi: 10.1007/s10577-011-9234-3

Yang EJ, Ha HK, Kang S-H (2014) Microzooplankton community structure and grazing impact on major phytoplankton in the Chukchi sea and the western Canada basin, Arctic ocean. Deep Sea Res Part II Top Stud Oceanogr 120:91-102. doi: 10.1016/j.dsr2.2014.05.020

Zane L, Ostellari L, Maccatrozzo L, et al (1998) Molecular Evidence for Genetic Subdivision of Antarctic Krill (Euphausia superba Dana) Populations. Proc Biol Sci 265:2387-2391.

Zane L, Ostellari L, Maccatrozzo L, et al (2000) Genetic differentiation in a pelagic crustacean (Meganyctiphanes norvegica: Euphausiacea) from the North East Atlantic and the Mediterranean 
Sea. Mar Biol 136:191-199. doi: 10.1007/s002270050676

Zane L, Patarnello T (2000) Krill: a possible model for investigating the effects of ocean currents on the genetic structure of a pelagic invertebrate. Can J Fish Aquat Sci 57:16-23. doi: 10.1139/f00-166 